\title{
A Strong Role for the AMOC in Partitioning Global Energy Transport and Shifting ITCZ Position in Response to Latitudinally Discrete Solar Forcing in CESM1.2 ${ }^{\circ}$
}

\author{
SungduK Yu ${ }^{\mathrm{a}}$ AND Michael S. PRITCHARD \\ Department of Earth System Sciences, University of California, University of California, Irvine, Irvine, California
}

(Manuscript received 3 June 2018, in final form 19 January 2019)

\begin{abstract}
Ocean circulation responses to interhemispheric radiative imbalance can damp north-south migrations of the intertropical convergence zone (ITCZ) by reducing the burden on atmospheric energy transport. The role of the Atlantic meridional overturning circulation (AMOC) in such dynamics has not received much attention. Here, we present coupled climate modeling results that suggest AMOC responses are of first-order importance to muting ITCZ shift magnitudes as a pair of hemispherically asymmetric solar forcing bands is moved from equatorial to polar latitudes. The cross-equatorial energy transport response to the same amount of interhemispheric forcing becomes systematically more ocean-centric when higher latitudes are perturbed in association with strengthening AMOC responses. In contrast, the responses of the Pacific subtropical cell are not monotonic and cannot predict this variance in the ITCZ's equilibrium position. Overall, these results highlight the importance of the meridional distribution of interhemispheric radiative imbalance and the rich buffering of internal feedbacks that occurs in dynamic versus thermodynamic (slab) ocean modeling experiments. Mostly, the results imply that the problem of developing a theory of ITCZ migration is entangled with that of understanding the AMOC's response to hemispherically asymmetric radiative forcing-a difficult topic deserving of focused analysis across more climate models.
\end{abstract}

\section{Introduction}

The meridional energy transport and its partitioning between ocean and atmosphere is a fundamental component of Earth system dynamics impacting climate in different latitudes as well as climate change. It has been studied theoretically (Bjerknes 1964; Stone 1978; Held 2001; Czaja and Marshall 2006; Vallis and Farneti 2009) and observationally (Vonder Haar and Oort 1973; Trenberth and Solomon 1994; Wunsch 2005); however, the response of the partitioning to external forcing has only begun to receive wide attention (Kay et al. 2016; Hawcroft et al. 2017; Tomas et al. 2016; Yang et al. 2017).

One important implication of the partitioning is that it is a key factor constraining how much the zonal-mean

Supplemental information related to this paper is available at the Journals Online website: https://doi.org/10.1175/JCLID-18-0360.s1.

\footnotetext{
${ }^{\text {a }}$ Current affiliation: Department of Geology and Geophysics, Yale University, New Haven, Connecticut.
}

Corresponding author: Sungduk Yu, sungduk.yu@yale.edu position of the intertropical convergence zone (ITCZ) can shift in response to a given hemispherically differential heating. Considering that the position of the ITCZ roughly coincides with the ascending branch of the Hadley circulation, such hemispheric heating imbalance can be lessened if the zonal-mean ITCZ migrates toward a warmer hemisphere since the thermally direct Hadley cell transports energy following the direction of its upper branch [i.e., the energetic framework; see Schneider et al. (2014) and Kang et al. (2018) for reviews]. However, the oceanic circulation-another degree of freedom in energy transport-can also alter the position of the zonal-mean ITCZ by reducing the burden of the atmospheric energy transport. In this article, we present results from an idealized experiment that is aimed to further understand the role of oceanic overturning circulations in the energy transport partitioning response to geographically structured and meridionally asymmetric top of atmosphere radiative forcing.

Recent global climate model (GCM) experiments have already shown that oceanic dynamics can damp ITCZ shift responses to high-latitude forcing by imposed cloud brightness (Kay et al. 2016), ocean albedo (Hawcroft et al. 2017), sea ice cover (Tomas et al. 2016), 
or stratospheric aerosols (Hawcroft et al. 2018). This is in contrast to studies that do not include ocean dynamics (e.g., Chiang and Bitz 2005; Broccoli et al. 2006; Kang et al. 2008, 2009), which naturally exhibit more pronounced ITCZ shifts to extratropical forcings. Damped ITCZ shifts occur in ocean-coupled general circulation models since perturbations to interhemispheric energy balance need not be restored by the atmosphere alone; they can also be buffered by changes in oceanic energy transport. The mechanical coupling between the Hadley cell and the oceanic subtropical cell (STC) via zonal surface wind stress has been attributed to one such damping effect (Held 2001; Schneider et al. 2014; Green and Marshall 2017; Schneider 2017; Kang et al. 2018). But the role of STC damping relative to other potentially important oceanic damping pathways, such as the Atlantic meridional overturning circulation (AMOC), remains unclear. Yet the observational evidence that the AMOC is fundamental to controlling the annual mean ITCZ location (Frierson et al. 2013; Marshall et al. 2014) motivates its likely importance.

Several modeling studies have already suggested important links between the AMOC and the ITCZ position. It has been known for decades that coupled GCM experiments subjected to freshwater hosing in the North Atlantic exhibit southward shifts of the ITCZ in association with a weakened AMOC (Manabe and Stouffer 1995; Vellinga and Wood 2002; Zhang and Delworth 2005; Chang et al. 2008; Zhang et al. 2010; Drijfhout 2010). More recently, Fučkar et al. (2013) argued that AMOC-type circulations determine the zonal-mean ITCZ position in an idealized limited-domain coupled GCM. Building on this work, Frierson et al. (2013) and Marshall et al. (2014) showed that the ITCZ position's annual mean tendency to lie north of the equator is a result of AMOC energy transport, using a combination of slab ocean aquaplanet and idealized coupled GCM tests, along with observational analysis. Other studies alluded to an important role of the AMOC in the ITCZ shift response to aerosol clean-up projected over the twenty-first century; for instance, the projected northward ITCZ shift due to relative warming of the North Atlantic from regional aerosol clean-up was shown to be smaller in the Atlantic than in the Pacific (Rotstayn et al. 2015; Allen 2015) and counteracted by weakening of the AMOC (i.e., cooling of the North Atlantic), ultimately muting the shift of annual-mean ITCZ position (McFarlane and Frierson 2017).

The above studies all hint at the potential for ITCZ shifts to be modulated by the AMOC's response to external radiative forcing. But questions remain about how significant this AMOC-linked pathway is. Indeed, much is yet to be discovered about how the AMOC responds in general to geographically structured radiative forcing at the top of atmosphere, as can occur through latitudinally sensitive cloud feedbacks to climate change, or some volcanoes, or through geoengineering by solar radiation management. Yet this may have implications for ITCZ shift dynamics.

We hypothesize that the AMOC plays an important role for muting ITCZ shifts in this context. Conceptually this is based on the fact that on long (e.g., decadal) time scales the AMOC variability is associated with buoyancy forcing (Buckley and Marshall 2016). This is in contrast to wind-driven variations in other circulation components such as the STC, whose variability is mainly driven by mechanical forcing via surface wind stress (McCreary and Lu 1994; Liu and Philander 1995). A consequence of mechanical coupling in the STC is that the cross-equatorial atmospheric and oceanic energy transports must positively covary (as illustrated in Figs. 1a and 1b). That is, the partitioning between atmospheric and oceanic responses cannot vary much through the STC coupling, assuming oceanic and atmospheric thermal structures do not change much. The AMOC is not subject to this mechanical constraint at a decadal time scale; rather its energy transport has the capacity to covary negatively with a given top-of-atmosphere heating imbalance (as illustrated in Figs. 1c and 1d). Thus, if the AMOC were to respond sensitively to the details of how a hemispherically asymmetric external forcing was geographically distributed, this could potentially act as a strong control on ITCZ shift damping efficiency, associated with changes in the overall ocean-atmosphere partitioning of the cross-equatorial energy transport response.

To probe this issue, we present results from a coupled climate model experiment with a highly idealized forcing, in which we artificially alter the top-of-atmosphere (TOA) energy budget through solar radiation modulation focused in discrete latitudinal bands at varying distances from the equator (Fig. 2a). The TOA insolation is perturbed to induce a northward energy transport by increasing (decreasing) the solar constant in the southern (northern) hemisphere. Such a perturbation is introduced at four different latitudinal bands occupying an equal area to examine partitioning responses to the different forcing locations. One additional experiment perturbing the whole hemisphere at a quarter of the magnitude (i.e., identical net interhemispheric heating asymmetry) is also performed. TOA forcing allows freedom for the simulated climate system to internally select its preferred partitioning of the required interhemispheric energy transport responses between the atmosphere and ocean (and, within the ocean, between the AMOC and other ocean circulation components). Our forcing is in some ways similar to that of Mechoso et al. (2016) and Xiang et al. (2018) (solar flux alteration) 
(a)

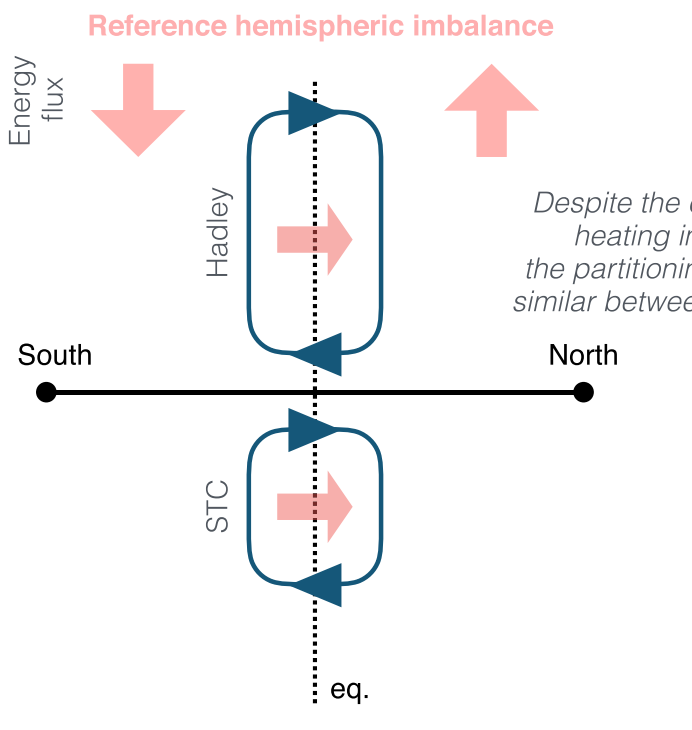

(c)

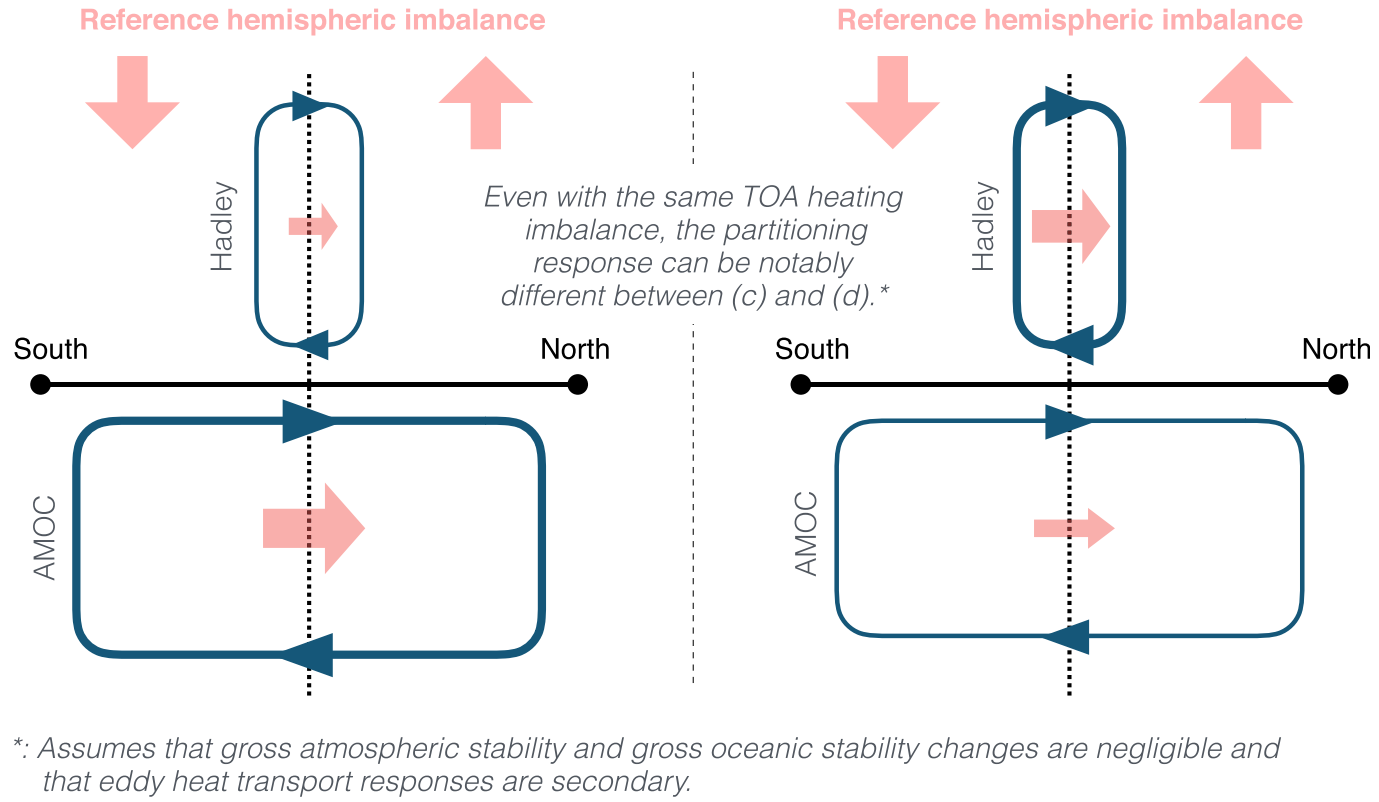

(b)

Stronger hemispheric imbalance 
and Haywood et al. (2016) and Hawcroft et al. (2018) (stratospheric aerosol management), but also with three notable differences-1) we only perturb the non-UV part of solar radiation to avoid a direct stratospheric perturbation that otherwise occurs, 2) we avoid net global perturbation by introducing both a solar flux source and sink, and 3) we integrate for long enough to sample AMOC responses [200 years, compared to 20 (Haywood et al. 2016), 25 (Mechoso et al. 2016), or 80 years (Hawcroft et al. 2018)].

Consistent with our hypothesis, the results will reveal a strong correlation between the magnitude of AMOC responses and the meridional distribution of interhemispheric forcing, which in turn explains a large degree of variance across the experiments in the degree of zonal-mean ITCZ shift response that occurs at equilibrium.

We acknowledge this work happens to precede the upcoming Extratropical-Tropical Interaction Model Intercomparison Project (ETINMIP; S. Kang 2017, personal communication), which aims to investigate intermodel diversity and mechanisms underlying the cross-equatorial energy transport partitioning and associated diversity of ITCZ shifts, by perturbing solar flux in different regions across an ensemble of independent GCMs. While the outcome of ETINMIP may help clarify the generality of some of our findings, the nature of our imposed forcing is also unique in some important ways, since we developed it independently. Specifically, the ETINMIP ensemble will apply a single band of cooling to discrete latitude regimes, whereas our experiments induce no net global mean perturbation of incoming solar radiation by using a pair of latitude bands (one cooling and warming) positioned at multiple distances from the equator. Thus we view our experiments here as very much complementary but not redundant, and hope some of the interpretation and analysis that we will demonstrate to be useful in our case may also prove likewise for analysis of the ETINMIP.

The rest of this paper is organized as follows. Section 2 contains the analysis methods as well as the description about the coupled GCM used for our simulations and the forcing designs. Section 3 shows the main results mainly contrasting the Atlantic Ocean and Pacific-Indian Ocean responses. Section 4 discusses the potential implications and limitations of our work and a comparison to previous results. Section 5 briefly summarizes this paper and concludes.

\section{Method}

\section{a. GCM simulations}

The Community Earth System Model (CESM) version 1.2.2. (Hurrell et al. 2013) is used, configured with interactive atmosphere, land, ocean, and sea ice components in a preindustrial experiment mode initialized with a spun-up ocean (i.e., the standard "B_1850_CAM5" component set).

A set of five experiments is forced with hemispherically asymmetric heating and cooling at the top of the simulated atmosphere (TOA). In each experiment, we introduce an artificial incoming non-UV shortwave energy source and sink pair at the TOA in the Southern and Northern Hemisphere. This is implemented by multiplying the baseline solar flux by a constant factor, designed to produce a perturbation magnitude of $17 \mathrm{~W} \mathrm{~m}^{-2}$ in the annual mean within forcing regions (Fig. 2a). This forcing is applied in different latitude ranges, by dividing each hemisphere into four zonal bands of equal area (tropical, subtropical, midlatitude, and high-latitude zones); these tests are named TROP, SUBTROP, MIDLAT, and HIGHLAT hereafter. In addition, we perform an extra experiment (WHOLE) in which the whole hemisphere is perturbed but at a quarter magnitude in order to keep the hemispherically integrated perturbation identical to other cases. Finally, a control simulation (CTRL) is conducted with no perturbation for the same period as experimental simulations. Each simulation is integrated for 200 years; just the last 150 years are used for analysis unless otherwise noted. Model simulation output and model code modification are available upon request.

Our decision to position the forcing at TOA is philosophically attractive as it maximizes the simulated climate system's freedom to excite internal feedbacks and to internally select the partitioning of the meridional energy transport response between atmosphere and ocean.

We acknowledge some relevant biases present in CESM that may influence the results of our study since the mean state sets the stage for both internal variability and its response to forced perturbations. We first point out that the ocean model [Parallel Ocean Program 2 (POP2); Smith et al. 2010] of CESM has some biases in its AMOC structure when forced by observed airsea fluxes. Compared to the ongoing RAPID AMOC observation (Cunningham et al. 2007), the modern observational atmospheric data forced POP2 simulation shows a somewhat shallower returning branch of AMOC (i.e., North Atlantic Deep Water) despite a realistic AMOC strength and mass transport profile above 2500-m depth (Danabasoglu et al. 2014). We also acknowledge CESM suffers from a double-ITCZ bias (Kay et al. 2016; Woelfle et al. 2018) of comparable magnitude to other CMIP5-era models (Zhang 2015; Stanfield 2016). That is, a spurious rainfall band is produced south of the equator in the central and southeast Pacific that is not observed, accompanied by a cold sea surface temperature (SST) bias along the central equatorial Pacific (Mechoso et al. 1995; Lin 2007; Li and Xie 2014). This issue is inescapable in 
(a) Insolation perturbation

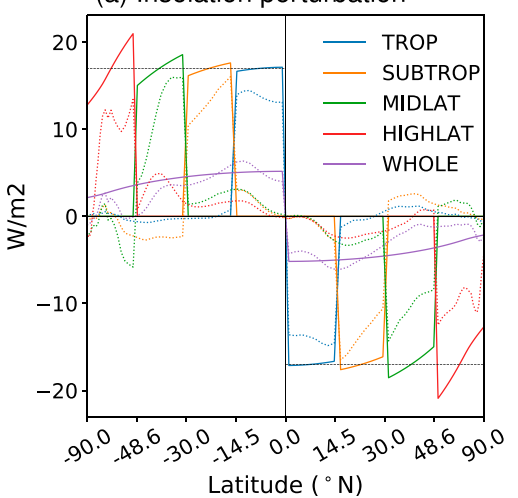

(b) Precipitation

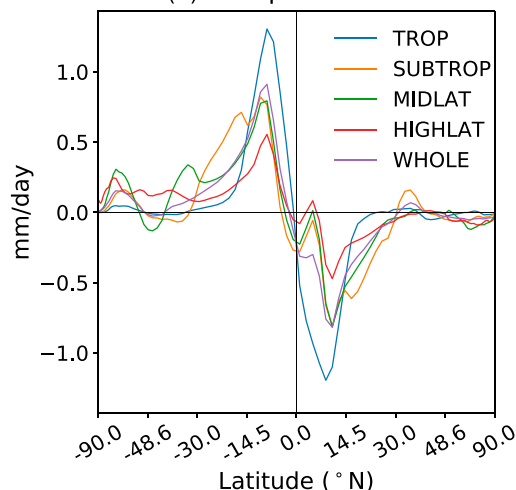

(c) Cross-equatorial heat transport

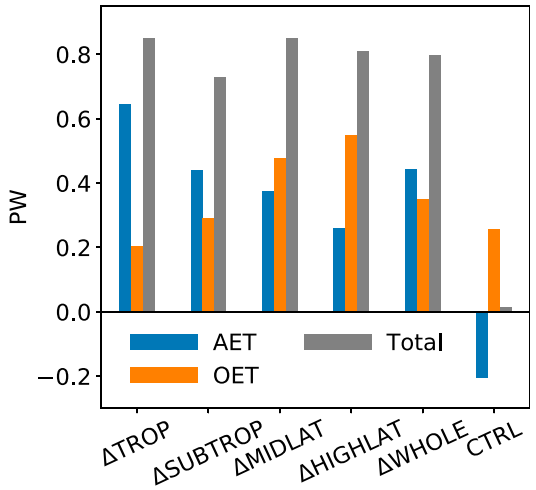

FIG. 2. (a) Climatological (years 51-200) zonal-mean, annual-mean TOA insolation perturbation (solid line) and net radiative flux responses (dotted line). (b) Climatological zonal-mean, annual-mean precipitation responses. (c) Climatological annual-mean crossequatorial energy transport responses of total (gray), atmosphere (blue), and ocean (orange); control results are shown as a baseline.

current-generation coupled GCMs but does limit the realism of our simulated system.

\section{b. Meridional energy transport calculation}

Monthly averaged data are used for all energy transport calculations so that the seasonal cycle is accounted as part of the time-mean meridional circulation component rather than being mistaken as an eddy contribution. The total, atmospheric, and oceanic meridional energy transports (TotalET, AET, and OET, respectively; $\mathrm{J} \mathrm{s}^{-1}$ or $\mathrm{W}$ ) are calculated as

$\operatorname{TotalET}(\phi)=$

$$
-\int_{\phi}^{\pi / 2} \int_{0}^{2 \pi}\left(R_{\mathrm{TOA}}-\frac{\partial E_{A}}{\partial t}-\frac{\partial E_{O}}{\partial t}\right) a^{2} \cos \phi d \theta d \phi
$$

$$
\begin{aligned}
& \operatorname{AET}(\phi)= \\
& -\int_{\phi}^{\pi / 2} \int_{0}^{2 \pi}\left(R_{\mathrm{TOA}}-R_{\mathrm{SURF}}-\frac{\partial E_{A}}{\partial t}\right) a^{2} \cos \phi d \theta d \phi, \quad \text { and }
\end{aligned}
$$

$$
\operatorname{OET}(\phi)=-\int_{\phi}^{\pi / 2} \int_{0}^{2 \pi}\left(R_{\mathrm{SURF}}-\frac{\partial E_{O}}{\partial t}\right) a^{2} \cos \phi d \theta d \phi
$$

where $R_{\mathrm{TOA}}$ is a downward net radiative flux at TOA, $R_{\text {SURF }}$ is a downward net surface flux (i.e., the sum of shortwave, longwave, latent, and sensible heat fluxes), and $E_{A}\left(E_{O}\right)$ is the column energy storage of atmosphere (ocean) per unit area.

\section{1) ATMOSPHERIC ENERGY TRANSPORT DECOMPOSITION}

The atmospheric energy transport is further decomposed into mean meridional circulation (MMC), stationary eddy, and transient eddy components [three terms on the right-hand side of Eq. (4)] based on

$$
\left[\overline{f_{A}}\right]=[\bar{V}][\bar{h}]+\left[\bar{V}^{*} \bar{h}^{*}\right]+\left[\overline{V^{\prime} h^{\prime}}\right],
$$

where $f_{A}$ is the meridional energy flux of atmosphere $\left(\mathrm{J} \mathrm{m}^{-2} \mathrm{~s}^{-1}\right), V$ is the northward mass flux $(\rho v$, where $\rho$ and $v$ are air density and northward wind speed, respectively; see appendix for how $V$ is obtained), and $h$ is the moist static energy (MSE), that is, $h=C_{p} T+L_{v} q+$ $g Z$, where $T, q$, and $Z$ are temperature, specific humidity, and geopotential height, respectively, and $C_{p}$, $L_{v}$, and $g$ are the specific heat of dry air at constant pressure, the latent heat of vaporization, and the acceleration due to gravity, respectively. Overlines and square brackets denote time and zonal averaging, respectively. The transient eddy component $\overline{V^{\prime} h^{\prime}}$ is obtained as a residual between the time-mean meridional energy flux $\overline{f_{A}}$ and the product of time-mean meridional mass flux $\bar{V}$ and time-mean MSE $\bar{h}$; that is, $\overline{V^{\prime} h^{\prime}}=\overline{f_{A}}-\bar{V} \bar{h}$. As the atmospheric model of the CESM uses a hybrid sigma vertical coordinate, variables are interpolated to a common pressure vertical coordinate before calculation.

The response (i.e., experiment minus control) of the mean meridional circulation energy flux $([\bar{V}][\bar{h}])$ is further decomposed into dynamic, thermodynamic, and nonlinear components [the three terms on the righthand side in Eq. (5)]:

$\Delta([\bar{V}][\bar{h}])=\Delta[\bar{V}][\bar{h}]_{\mathrm{ctrl}}+[\bar{V}]_{\mathrm{ctrl}} \Delta[\bar{h}]+\Delta[\bar{V}] \Delta[\bar{h}]$,

where $\Delta(\cdots)$ denotes the experiment simulation output minus control simulation output and subscript "ctrl" denotes the control simulation.

The MMC energy flux is also used to calculate the atmospheric gross moist stability (GMS), that is, a measure of the efficiency of the time-mean circulation in achieving meridional MSE transport. Following Merlis et al. (2013) and Hill et al. (2015), the GMS is calculated as 


$$
\operatorname{GMS}(\phi)=\frac{\int_{p_{T}}^{p_{S}}[\bar{V}][\bar{h}] d p / g}{\Psi_{\max }},
$$

that is, in the form sometimes referred to as "mean" GMS (Frierson 2007; Merlis et al. 2013; Xiang et al. 2018), where $\Psi_{\max }$ is the extremum of the zonal-mean mass streamfunction of the atmosphere at a given latitude. By convention, which presumes a simple overturning structure (e.g., one upper branch and one lower branch with opposite direction), the GMS governs the energy transport efficiency of the Hadley circulation and positive GMS ensures that the direction of energy transport follows that of the upper branch of Hadley circulation. Note that some studies use a different definition of GMS (so-called "total" GMS) by using the total AET, which also includes eddy energy transports (e.g., Kang et al. 2009; Seo et al. 2017). We choose to use the socalled mean GMS since it is more easily interpreted and in any case we will analyze eddy energy transport terms separately. But one should take caution when comparing results based on different flavors of GMS; there exist several ways of defining it (e.g., Neelin and Held 1987; Raymond et al. 2009).

\section{2) OCEANIC ENERGY TRANSPORT DECOMPOSITION}

OET is decomposed into mean circulation and eddy components similar to Eq. (4):

$$
\overline{f_{O}}=\bar{V} \overline{h_{O}}+\overline{V^{\prime} h_{O}^{\prime}},
$$

where $f_{O}$ is the meridional advective energy flux of the ocean, $V$ is the northward mass flux, and $h_{O}$ is the oceanic energy; that is, $h_{O}=C_{p, \mathrm{sw}} \theta$, where $C_{p, \mathrm{sw}}$ and $\theta$ are the specific heat capacity of seawater and the potential temperature. Note that $V$ is calculated as a product of meridional current speed and the density of seawater, which is assumed to be a constant $\left(1.026 \mathrm{~g} \mathrm{~cm}^{-3}\right)$ for our calculation - this is a fine assumption since the variation of density is much smaller than that of $V$ due to the near incompressibility of seawater. The term $V$ includes both resolved (Eulerian-mean advection) as well as parameterized (mesoscale and sub-mesoscale eddy-induced advection) components, but the parameterized component is relatively small in the mean.

The response of Eulerian-mean energy flux $\bar{V} \overline{h_{O}}$ is further decomposed into dynamic, thermodynamic, and nonlinear components, that is,

$$
\Delta\left(\bar{V} \overline{h_{O}}\right)=\Delta \bar{V} \overline{h_{O, \mathrm{ctrl}}}+\overline{V_{\mathrm{ctrl}}} \Delta \overline{h_{O}}+\Delta \bar{V} \Delta \overline{h_{O}}
$$

\section{c. Tropical precipitation asymmetry index}

Following Hwang and Frierson (2013), a precipitation asymmetry index (PAI) is calculated as the area-weighted mean precipitation rate difference between north $\left(0^{\circ}-\right.$ $\left.20^{\circ} \mathrm{N}\right)$ and south $\left(20^{\circ} \mathrm{S}-0^{\circ}\right)$, then normalized by the areaweighted mean precipitation rate of the whole tropics $\left(20^{\circ} \mathrm{S}-20^{\circ} \mathrm{N}\right)$. Accordingly, the PAI captures the relative strength of the two solstice season ITCZ positions, which we will loosely refer to as the positions of the annual- and zonal-mean ITCZ. The responses of the PAI are well correlated with that of the tropical precipitation centroid (see Fig. S1 in the online supplemental material), which is another popular measure of annual-mean ITCZ position; none of our main findings are sensitive to which proxy is used for the zonal-mean ITCZ position.

\section{Results}

We begin by analyzing the annual-mean ITCZ precipitation response across the experiment ensemble using the last 150-yr average. A southward ITCZ "shift," a term we will use as shorthand to describe an increase (decrease) in intensity of the southern (northern) zonal-mean, annual-mean rainfall band, is observed in all cases-as expected by the northward cross-equatorial atmospheric energy transport $\left(\mathrm{AET}_{\mathrm{eq}}\right)$ response to warming (cooling) the Southern (Northern) Hemisphere (Fig. 2a). However, its magnitude monotonically decreases as the forcing bands are moved poleward (Fig. 2b). This differing ITCZ shift response occurs despite the fact that the magnitude of incoming solar forcing asymmetry is constrained to be identical across the experiments.

This implies that either 1) latitudinally varying internal radiative feedbacks modify the effective magnitude of the asymmetric forcing across experiments and/ or 2) the cross-equatorial oceanic energy transport $\left(\mathrm{OET}_{\mathrm{eq}}\right)$ response is sensitive to the geographic details of the forcing. The effective forcing at equilibrium (i.e., net TOA radiative anomalies after radiative feedbacks at equilibrium) mostly determines the cross-equatorial total energy transport since oceanic heat content change is very small (Fig. 3). While the effective forcing does show some variation across experiments, there is remarkably little spread in its net interhemispheric asymmetry (Figs. 2a,c) with a range of $2.90-3.38 \mathrm{~W} \mathrm{~m}^{-2}$ as a result of compensating internal radiative feedbacks (Fig. 3). This is interestingly inconsistent with the results of Seo et al. (2014), in which latitudinally sensitive cloud feedbacks were able to exert strong control of the TOA radiative budget and AET due to the use of a slab ocean model; the implication is that dynamic oceanic buffering is very important to the global energetics. For our own 


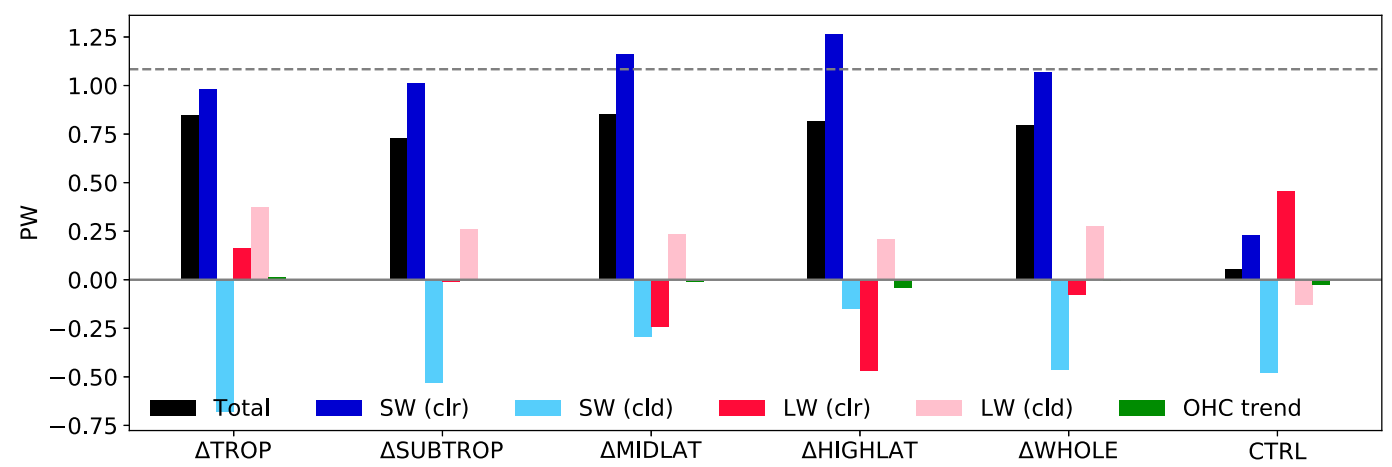

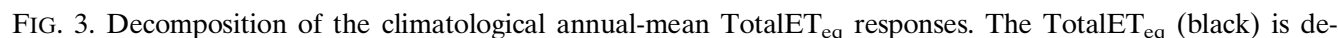
composed into energy transports due to clear-sky shortwave flux (blue), shortwave cloud radiative effect (CRE) (light blue), clear-sky longwave flux (red), longwave CRE (light red), and oceanic heat content (OHC) trend (green). The $\Delta$ means experiment minus control. Shortwave and longwave fluxes are calculated at the top of atmosphere.

purposes, the main point is that such internal radiative feedback can only explain about $0.12 \mathrm{PW}$ spread in the total (oceanic plus atmospheric) cross-equatorial energy transport responses, arguing against the first possibility. In contrast, the spread of $\mathrm{AET}_{\mathrm{eq}}$ alone is much larger (0.39 PW; Fig. 2c), implying that the variability in the annual-mean ITCZ shift response is caused by the variability in the $\mathrm{OET}_{\mathrm{eq}}$ responses across the experiments.

In short, so far we have found that the cross-equatorial energy transport partitioning between ocean and atmosphere becomes a key factor that determines the magnitude of ITCZ shift in our experiments: When hemispherically asymmetric solar forcing is concentrated at higher latitudes, the partitioning of the coupled response becomes more ocean-centric and thus the ITCZ shift response becomes more muted. The question naturally arises as to why.

\section{a. The different responses from the Atlantic and Pacific-Indian Oceans}

Figure 4 shows that Atlantic dynamics play a leading role in driving the tendency toward a more ocean-centric energy transport response with higher latitude forcing. To understand the role of each ocean, the basin-specific $\mathrm{OET}_{\text {eq }}$ responses are decomposed into dynamic and thermodynamic components [Fig. 4; Eq. (8)]-note that, consistent with observational estimates (Jayne and Marotzke 2002), the transient eddy $\mathrm{OET}_{\mathrm{eq}}$ responses are very small [gray bars in Fig. 4; Fig. S2; Eq. (7)]. The $\mathrm{OET}_{\text {eq }}$ responses to changing the latitudinal position of hemispherically asymmetric forcing are mostly driven by dynamic changes, not thermodynamic ones. But different ocean basins respond differently. Only the Atlantic shows a clear monotonic sensitivity across experiments in line with the global $\mathrm{OET}_{\mathrm{eq}}$ sensitivity. In contrast, the Pacific-Indian $\mathrm{OET}_{\mathrm{eq}}$ does not exhibit a monotonic sensitivity, except during the transition from SUBTROP to MIDLAT, during which both the Atlantic and PacificIndian basins show comparable $\mathrm{OET}_{\mathrm{eq}}$ increases. Despite the fact that the absolute magnitude of the Atlantic $\mathrm{OET}_{\mathrm{eq}}$ response is generally smaller than that of the Pacific-Indian response, normalized by its respective basin width the Atlantic is a much more efficient energy (a) Global

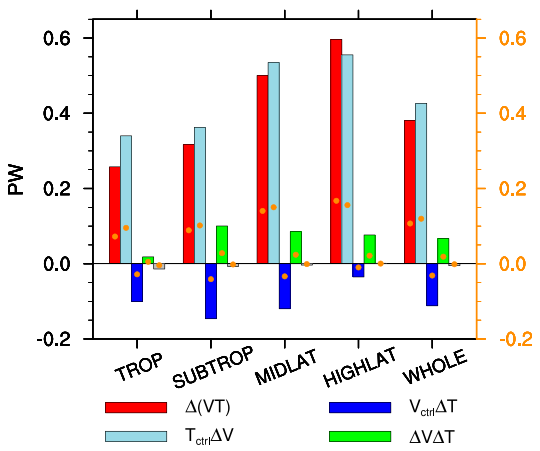

(b) Atlantic

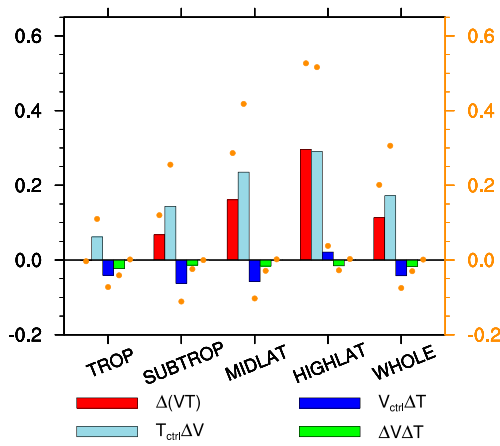

(c) Pacific-Indian

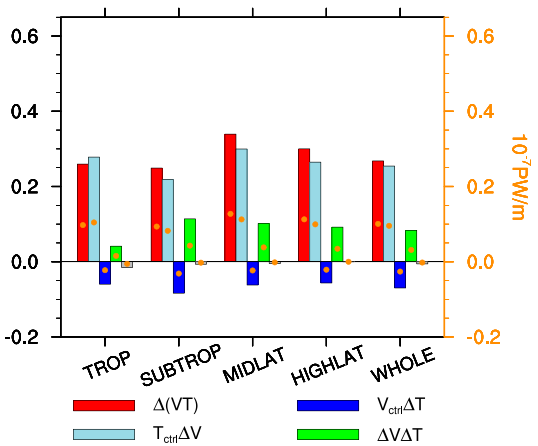

FIG. 4. Climatological annual-mean $\mathrm{OET}_{\text {eq }}$ responses of (a) global, (b) Atlantic, and (c) Pacific-Indian Oceans (unit: PW). Different colors show different components of $\mathrm{OET}_{\text {eq }}$ : total (red), dynamic (light blue), thermodynamic (deep blue), and nonlinear (green). Transient eddy transport responses are shown in gray bars (rightmost bars for each experiment). Yellow dots are for OET eq $_{\text {normalized by }}$ basin width (unit: $10^{-7} \mathrm{PW} \mathrm{m}^{-1}$ ). 

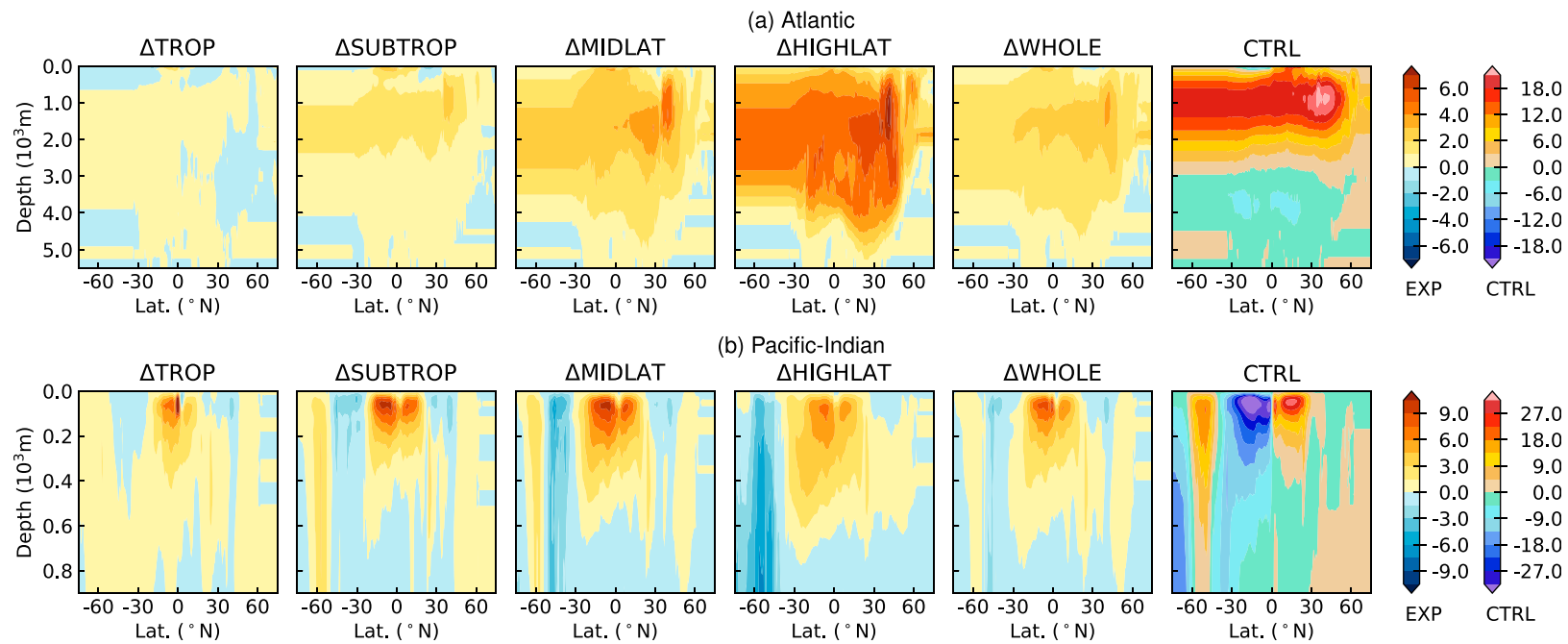

FIG. 5. Climatological annual-mean meridional overturning streamfunction responses (experiment minus control) for the (a) Atlantic and (b) Pacific-Indian basins; rightmost panels show the baseline streamfunction of the control simulation (CTRL) in each basin (Sv; $1 \mathrm{~Sv} \equiv 10^{6} \mathrm{~m}^{3} \mathrm{~s}^{-1}$ ). Warm (cold) colors are signed as clockwise (counterclockwise) circulations. Note that (a) and (b) have different depths and color bars. The coherence of extratropical (off-equatorial) and equatorial responses of AMOC (STC) is shown in Fig. S4.

transporter (orange dots in Fig. 4) and seems to play a controlling role in producing ITCZ shift variance across our experiments.

This draws our analysis toward the AMOC because it is the main dynamical pathway of meridional oceanic energy transport in the Atlantic. Consistent with the Atlantic $\mathrm{OET}_{\mathrm{eq}}$, the AMOC response becomes monotonically stronger as the solar forcing bands are moved poleward (Fig. 5a). Transient analysis shows this monotonic sorting with forcing latitude emerges within 30 years (Fig. 6a) and persists for two centuries amidst multidecadal internal variability. There is reassuring consistency in the unsteady evolution of the anomalous Atlantic $\mathrm{OET}_{\mathrm{eq}}$ and AMOC circulation strength (Figs. 6a,b).

Unlike the AMOC responses, the Pacific-Indian STC responses do not exhibit a monotonic sensitivity with implications for its $\mathrm{OET}_{\mathrm{eq}}$ responses (Fig. 6c). While tantalizing changes in the STC circulation response do occur (Fig. 5b; also, note the hemispherically asymmetric component shown in Fig. S3), no associated $\mathrm{OET}_{\text {eq }}$ responses are detectable (Fig. 6d); that is, a strengthening (weakening) of STC does not lead to a larger (smaller) $\mathrm{OET}_{\text {eq. This implies that internal }}$ compensations exist between the structure of the STC response and its energy transport response. The compensation mechanisms are case specific. For instance, compared to SUBTROP and MIDLAT, a weaker response of circulation strength in HIGHLAT is compensated by a deepening of circulation response-which increases the energy transport efficiency by enhancing the temperature difference between the upper and lower branches. A separate mechanism buffers the
TROP experiment via spinup of a strong cross-equatorial roll-type circulation near the equator (Miyama et al. 2003) that acts against the weaker response of STC circulation strength.

\section{b. Different time scales of Pacific and Atlantic responses and variability}

We have found a leading role for the AMOC in controlling the climatological sensitivity of zonal-mean ITCZ shifts across our experiments. We now separately examine several time scales of the response and its internal variability. A complex mixture of time scales is expected to be at play since AMOC variability is mainly driven by buoyancy (wind) forcing on decadal (subannual) time scales (Buckley and Marshall 2016; Pillar et al. 2016) whereas STC variability tends to be dominated by wind forcing on interannual time scales (Schott et al. 2007) but with the potential to also produce extratropical forcing on decadal time scales (Nonaka et al. 2002; Thomas and Fedorov 2017).

In Fig. 7, scatterplots of key predictors of tropical precipitation asymmetry both within experiments (i.e., dots of one color) and across experiments (i.e., dots spanning multiple colors) provide an especially compact way to contrast the differing roles of the two ocean basins on multidecadal (top) versus interannual (bottom) time scales.

The decomposition of the global relationship between PAI and $\mathrm{OET}_{\text {eq }}$ on long time scales shows that the Atlantic clearly controls the equilibrium state response to the TOA forcing (monotonic color ranking along statistically significant interexperiment regression line in 
(a) AMOC strength

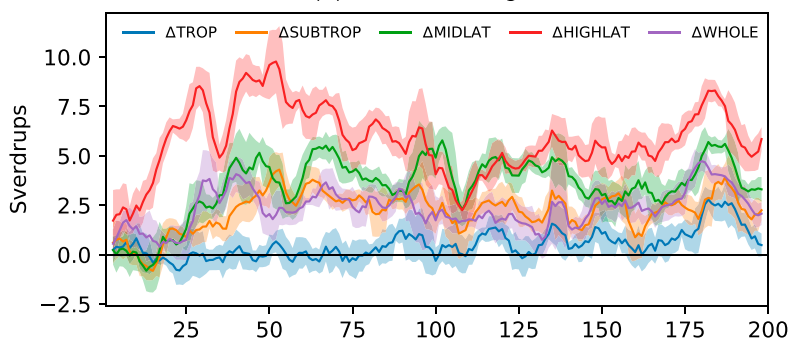

(b) Atlantic cross-equatorial $\mathrm{OHT}$

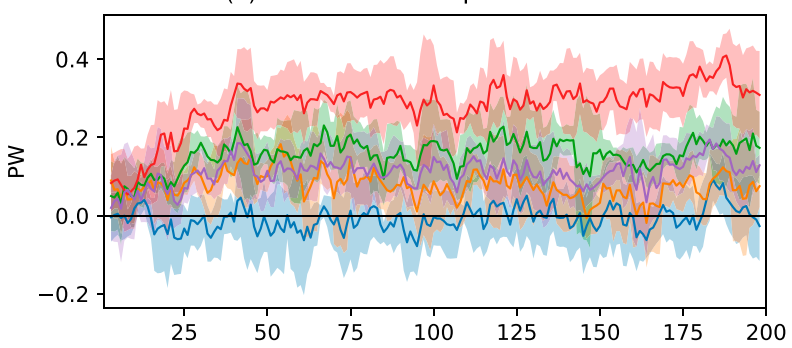

(c) STC strength

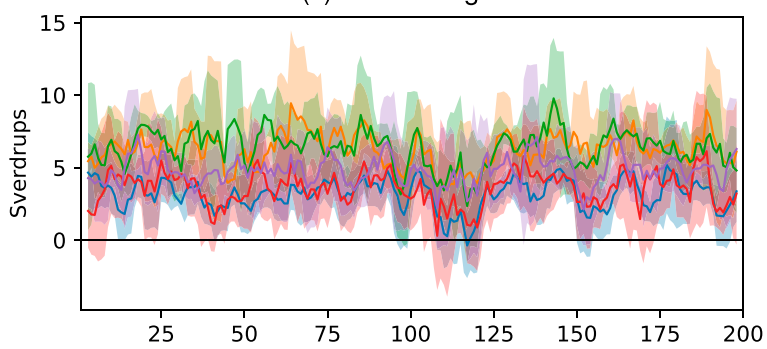

(d) Pacific-Indian cross-equatorial $\mathrm{OHT}$

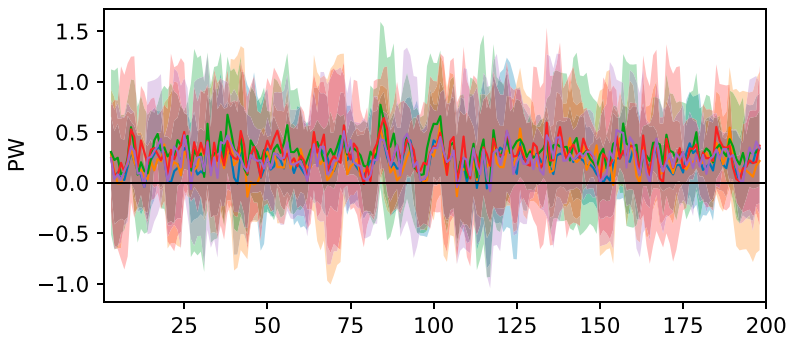

FIG. 6. Time series of (a) the AMOC strength, (b) Atlantic $\mathrm{OET}_{\text {eq }}$, (c) Pacific-Indian asymmetric subtropical cell strength, and (d) Pacific-Indian $\mathrm{OET}_{\text {eq }}$ responses (experiment minus control). A solid line shows the 5-yr running mean, and the shading is \pm 1 of the 5-yr running standard deviation. AMOC strength is defined as the maximum overturning streamfunction within $30^{\circ}-50^{\circ} \mathrm{N}$ latitude and $600-1400-\mathrm{m}$ depth in the Atlantic. The Pacific-Indian asymmetric subtropical cell strength is defined as a maximum of asymmetric component of overturning streamfunction (see Fig. S3) within $7^{\circ}-15^{\circ} \mathrm{N}$ latitude and $0-250-\mathrm{m}$ depth in the Pacific-Indian basin.

Figs. 7a, b), whereas the Pacific-Indian $\mathrm{OET}_{\mathrm{eq}}$ cannot detectably predict the global PAI variance within noise (Fig. 7c). Interestingly, a positive cross-experiment correlation between PAI and Atlantic $\mathrm{OET}_{\text {eq }}$ responses is not found within each experiment (dots of a single color) in Fig. 7b, suggesting that the fixed TOA forcing does not impact the decadal variability of AMOC activity but just its equilibrium attractor. It is unclear why PAI (and accordingly $\mathrm{AET}_{\mathrm{eq}}$ ) variability are not correlated with Atlantic $\mathrm{OET}_{\text {eq }}$ variability, but we speculate that the OET variability might balance with the oceanic column energy storage variability rather than the surface heat flux variability [Donohoe et al. 2014; see also Eq. (3)].

On short time scales, a robust regression is detected within each experiment between Pacific-Indian $\mathrm{OET}_{\text {eq }}$ and global PAI responses (colored regression lines in Figs. 7d,f), while the Atlantic $\mathrm{OET}_{\mathrm{eq}}$ responses do not contribute to the PAI responses (Fig. 7e). This time scale separation between the two ocean basins is robust to variations of the exact running mean windows used to discriminate short- from long-term behavior, although the long-term Atlantic correlation reaches its maximum around a 10-yr running mean window (Fig. $7 \mathrm{~g}$ ).

The opposite signs of the PAI-OET ${ }_{\text {eq }}$ correlation for the Atlantic (across experiments) versus the PacificIndian Oceans (within experiments) illustrate the fundamental difference of AMOC versus STC freedom to damp ITCZ shifts that was alluded to in the introduction and in Fig. 1. Keeping in mind that a more negative PAI implies a more southward ITCZ position and a more positive (northward) $\mathrm{AET}_{\mathrm{eq}}$ (Fig. S5), the regressions in Fig. 7 show that Atlantic OET $_{\text {eq }}$ negatively covaries with $\mathrm{AET}_{\text {eq }}$, whereas Pacific-Indian $\mathrm{OET}_{\text {eq }}$ positively co-

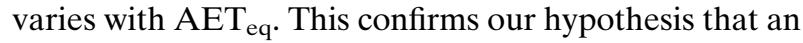
AMOC response has the capacity to be an efficient ITCZ shift damping mechanism (Fig. 1), as it can significantly alter the partitioning between atmospheric and oceanic energy transport.

We note that the cross-experiment correlation between the PAI and the Atlantic OET eq $_{\text {responses (Fig. 7b) does }}$ not depend on the fact that the magnitude of effective radiative forcing (i.e., including all feedbacks) — which dictates the total cross-equatorial energy transport (TotalET eq $_{\text {) }}$ magnitude - happens to be similar across our experiments (e.g., Fig. 2c). While the magnitudes of $\triangle \mathrm{AET}_{\mathrm{eq}}$ and $\Delta \mathrm{OET}_{\text {eq }}$ are constrained by the effective forcing magnitude $\left(\Delta \mathrm{AET}_{\mathrm{eq}}+\Delta \mathrm{OET}_{\mathrm{eq}}=\Delta\right.$ TotalET $\left._{\mathrm{eq}}\right)$, the partitioning between $\Delta \mathrm{AET}_{\text {eq }}$ and $\Delta \mathrm{OET}_{\text {eq }}$ is not; that is,

$$
\frac{\Delta \mathrm{AET}_{\mathrm{eq}}}{\Delta \text { TotalET }_{\text {eq }}}+\frac{\Delta \mathrm{OET}_{\mathrm{eq}}}{\Delta \text { TotalET }_{\text {eq }}}=1,
$$

implying that the negative covariance between the normalized quantities is guaranteed despite the fact that the covariance of the unnormalized quantities depends on the magnitude of $\Delta$ TotalET $_{\text {eq }}$. Assuming 1) that the Hadley circulation energy transport dominates the crossequatorial atmospheric energy transport $\left(\Delta \mathrm{AET}_{\mathrm{eq}}=\right.$ $\Delta \mathrm{AET}_{\mathrm{eq}}^{\mathrm{HC}}+\Delta \mathrm{AET}_{\mathrm{eq}}^{\mathrm{EDDY}} \approx \Delta \mathrm{AET}_{\mathrm{eq}}^{\mathrm{HC}} ;$ Fig. $\left.8 \mathrm{a}\right), 2$ ) that the 
(a) Global (long)

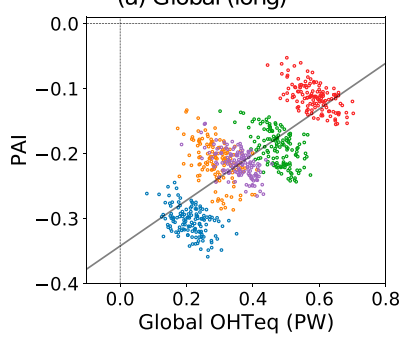

(d) Global (short)

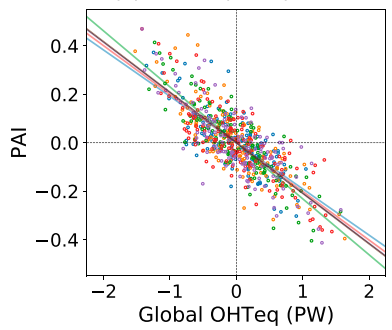

(b) Atlantic (long)

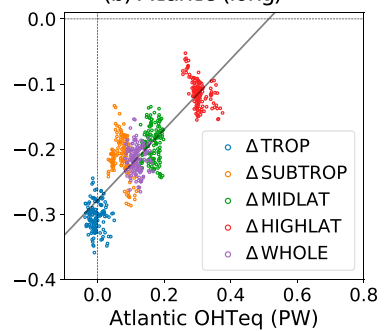

(e) Atlantic (short)

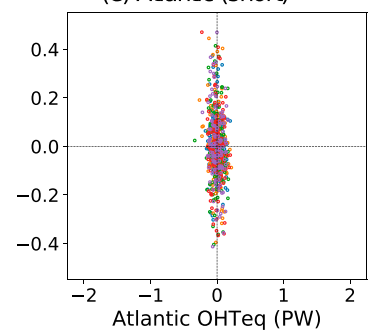

(c) Pacific-Indian (long)

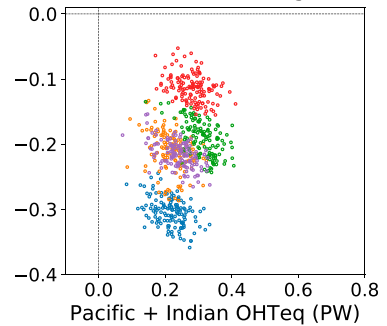

(f) Pacific-Indian (short)

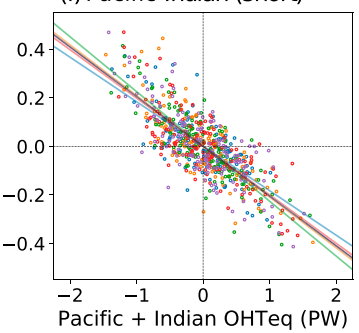

(g) Correlation

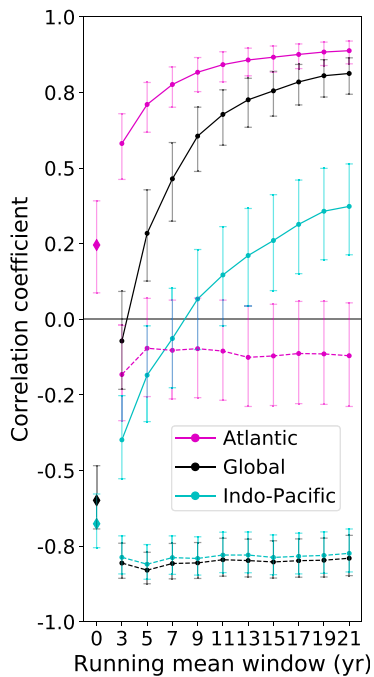

FIG. 7. Scatterplots of annual-mean time series of tropical PAI vs OET $_{\text {eq }}$ during years 51-200: (top) long-term component defined as 15-yr running average and (bottom) short-term component defined as anomalies from the long-term component, for (a),(d) global ocean, (b),(e) Atlantic Ocean, and (c),(f) Pacific and Indian Ocean. Regression lines for all experiments (gray) and for each experiment (color) are shown only for relationships with $r^{2}$ greater than 0.5. (g) Correlation coefficients $r$ (using all experiments) of long term (solid line) and short term (dashed line) with different running mean window lengths (zero running mean window length means original annual mean time series). Errors bars are the $95 \%$ confidence interval.

cross-equatorial oceanic energy transport is mostly driven by two oceanic overturning circulations $\left(\Delta \mathrm{OET}_{\mathrm{eq}} \approx\right.$ $\left.\Delta \mathrm{OET}_{\mathrm{eq}}^{\mathrm{STC}}+\Delta \mathrm{OET}_{\mathrm{eq}}^{\mathrm{AMOC}}\right)$, and 3) that $\mathrm{AET}_{\mathrm{eq}}^{\mathrm{HC}}$ and $\mathrm{OET}_{\mathrm{eq}}^{\mathrm{STC}}$ are coupled $\left(\Delta \mathrm{OET}_{\mathrm{eq}}^{\mathrm{STC}} \approx \alpha \Delta \mathrm{AET}_{\mathrm{eq}}^{\mathrm{HC}}\right.$; Held 2001), Eq. (9) can be simplified to

$$
(1+\alpha) \frac{\Delta \mathrm{AET}_{\mathrm{eq}}^{\mathrm{HC}}}{\Delta \text { TotalET }_{\mathrm{eq}}}+\frac{\Delta \mathrm{OET}_{\mathrm{eq}}^{\mathrm{AMOC}}}{\Delta \text { TotalET }_{\mathrm{eq}}}=1,
$$

where the superscripts HC, EDDY, STC, and AMOC denote energy transport components due to the Hadley circulation, eddies, the subtropical cell, and the Atlantic meridional overturning circulation, respectively, and $\alpha$ is a

(a)

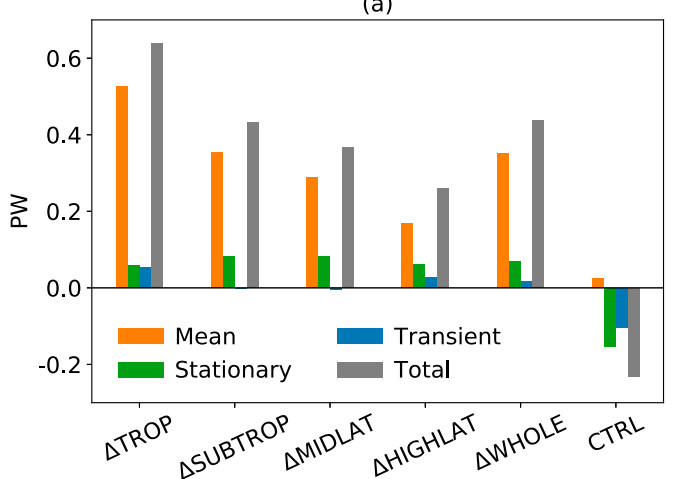

positive definite parameter or function. Accordingly, we expect to see a similarly tight, if not tighter, correlation between PAI and Atlantic $\mathrm{OET}_{\mathrm{eq}}$ when normalizing $\mathrm{OET}_{\mathrm{eq}}$ by the effective forcing magnitude $\left(\Delta \mathrm{TotalET}_{\mathrm{eq}}\right)$; indeed this is confirmed in Fig. S6.

\section{Discussion}

\section{a. Tightness of the relationship between cross- equatorial AET and zonal-mean ITCZ position}

The relationship between $\mathrm{AET}_{\mathrm{eq}}$ and zonal-mean ITCZ position (Fig. S5) plays a key role in connecting the energy transport partitioning responses to the ITCZ

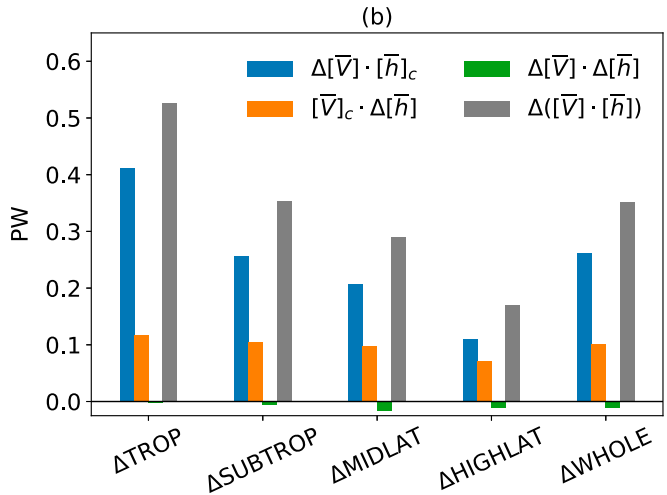

FIG. 8. (a) Decomposition of the climatological annual-mean $\mathrm{AET}_{\text {eq }}$ (gray) into meridional mean circulation (orange), stationary eddy (green), and transient eddy (blue) components. (b) The decomposition of the meridional mean circulation $\mathrm{AET}_{\mathrm{eq}}$ (gray) into dynamic (blue), thermodynamic (orange), and nonlinear (green) terms. The $\Delta$ means experiment minus control. 
(a) GMS
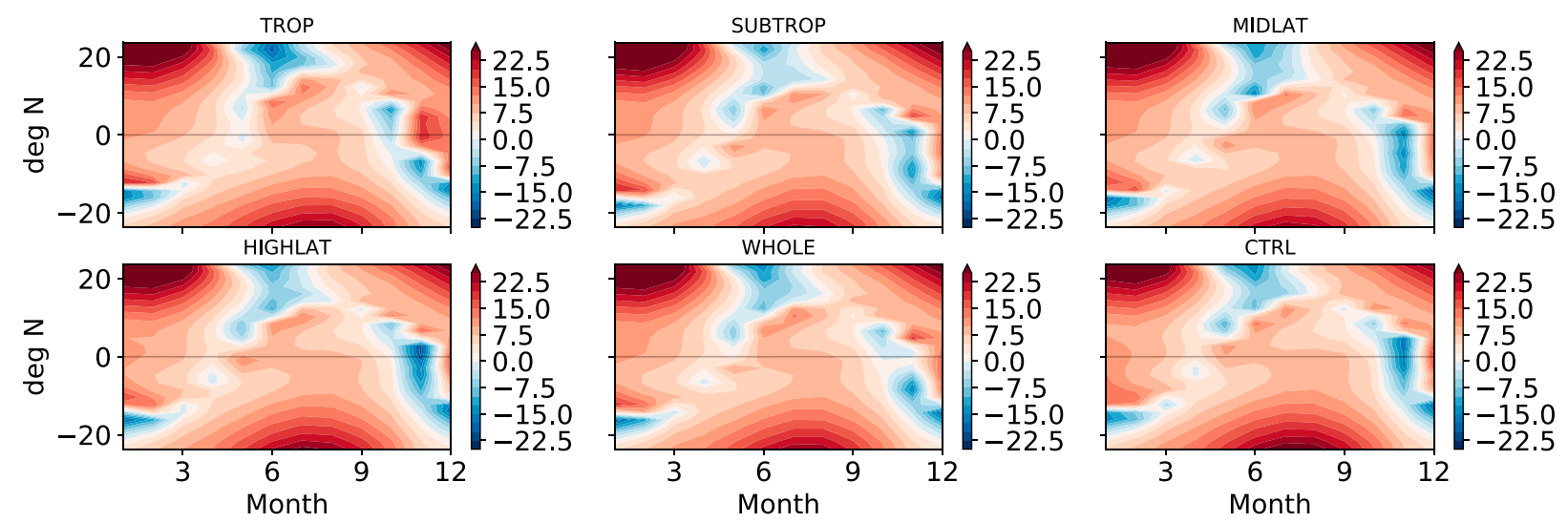

(b) GMS at the equator

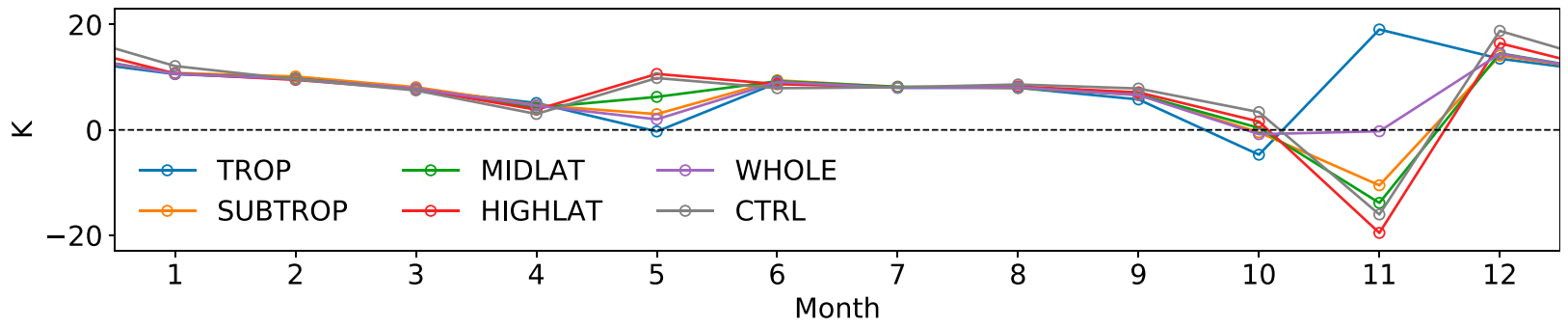

FIG. 9. (a) The climatological seasonal cycle of GMS (unit: K) and (b) intercomparison across experiments of on-equatorial values. GMS is calculated independently for each month using Eq. (6) and composited into a climatological seasonal cycle.

shift. Accordingly, we need to confirm whether it is appropriate to view relationships between $\mathrm{AET}_{\mathrm{eq}}$ and ITCZ across our experiments through the energetic framework (Broccoli et al. 2006; Kang et al. 2008, 2009; Donohoe et al. 2013). This acknowledges that there can be special cases where such a framework can be inappropriate, for instance if the eddy energy transport dominates the time-mean Hadley circulation energy transport (Roberts et al. 2017; Xiang et al. 2018) or if the energy transport efficiency of the Hadley circulation (i.e., the gross moist stability) dominates spread in the $\mathrm{AET}_{\text {eq }}$ response (Merlis et al. 2013; Seo et al. 2017). However we will show that the $\mathrm{AET}_{\text {eq }}$ response is a good proxy for a zonal-mean ITCZ shift response in our experiment, by showing secondary responses of eddy energy transport and GMS.

Both the transient and the stationary eddy $\mathrm{AET}_{\mathrm{eq}}$ responses are much weaker than the Hadley circulation (i.e., MMC) $\mathrm{AET}_{\text {eq }}$ responses in our experiments in the annual mean [Fig. 8a; Eq. (4)]. We further decompose the mean circulation $\mathrm{AET}_{\mathrm{eq}}$ into its dynamic and thermodynamic components to confirm whether the Hadley circulation $\mathrm{AET}_{\mathrm{eq}}$ is due to the response of circulation [Fig. 8b; Eq. (5)]. The dynamic components clearly dominate the Hadley cell $\mathrm{AET}_{\mathrm{eq}}$ responses in all simulations. On the other hand, the thermodynamic responses are secondary and insensitive to the forcing latitudes.

The smallness of the thermodynamic component in the Hadley cell $\mathrm{AET}_{\text {eq }}$ responses implies a weak variation of GMS across our experiments, confirmed by a direct analysis of GMS computed along the equator (Fig. 9). For most calendar months, positive GMS (i.e., stable stratification) along the equator is observed; this ensures that the direction of energy transport follows that of the upper branch of Hadley circulation in all simulations. A brief period of diverging GMS (and even negative GMS) across simulations occurs just before the beginning of each solstice, during May and November (Fig. 9b). We interpret this as a consequence of the lag between the seasonal cycles of heat transport and mass transport [see Eq. (6)]. Such lags might be expected as a result of reorganized overturning circulation with shallow overturning branches during the shoulder seasons (Wei and Bordoni 2018) or the zonally asymmetric responses of the overturning structure (Heaviside and Czaja 2013; Shaw et al. 2015). Interestingly, the GMS excursion during the shoulder seasons is monotonically larger for lower-latitude forcing experiments.

It is important to verify that the annual-mean responses are consistent through the seasonal cycle, since 
(a) The annual cycle of precipitation asymmetry index

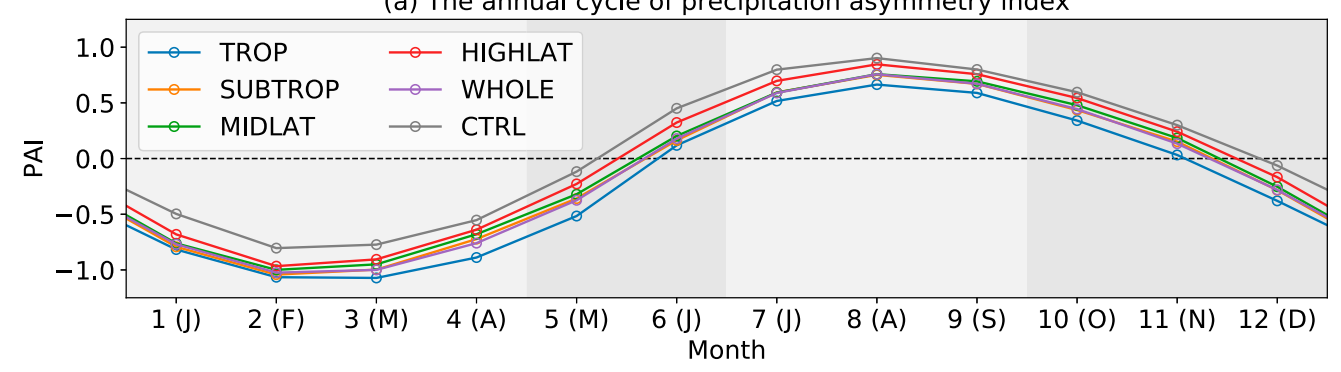

(b) JFMA

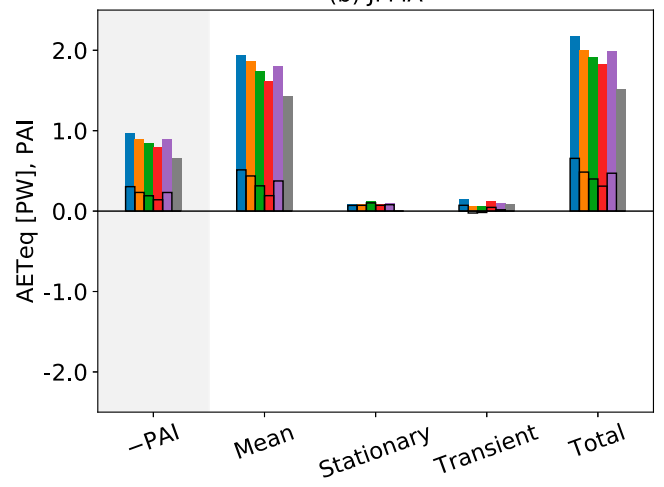

(d) JAS

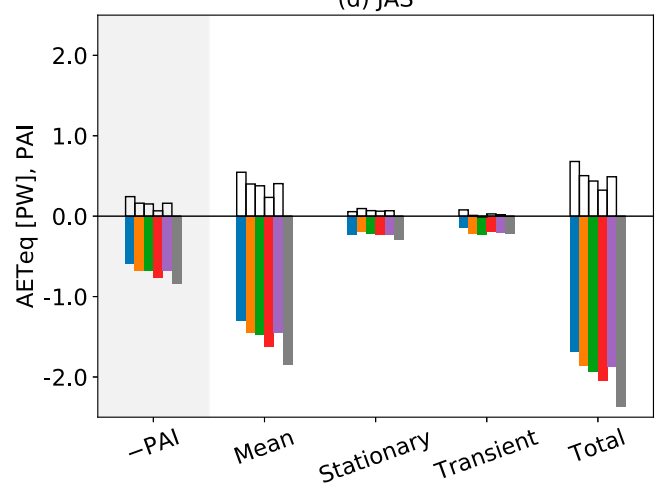

(c) MJ

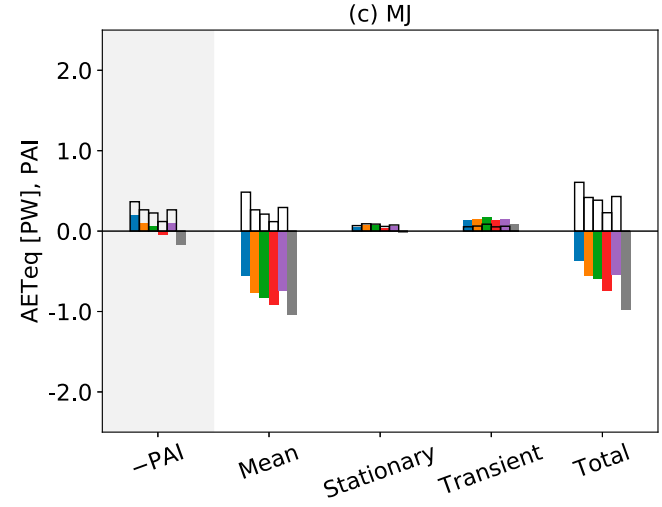

(e) OND

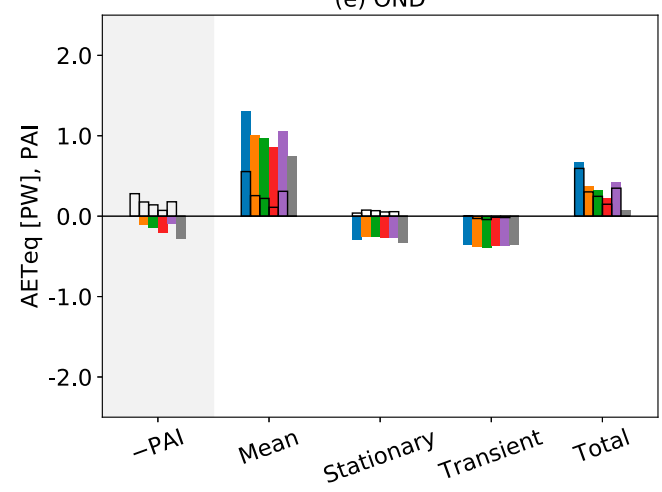

FIG. 10. (a) Climatological seasonal cycle of the tropical PAI. Decomposition of seasonal AET eq into mean meridional circulation, stationary eddy, and transient eddy components during (b) JFMA, (c) MJ, (d) JAS, and (e) OND. The empty bars are the responses (i.e., experiment minus control).

it is possible that the annual-mean Hadley circulation and its associated $\mathrm{AET}_{\text {eq }}$ could simply represent the sum of two opposing solstice-season responses. To this end, Figs. 10b-e decompose the annual-mean AET $_{\text {eq }}$ (Fig. 8a) into seasonal categories based on PAI (Fig. 10a), that is, two solstice seasons [January-April (JFMA) and July-September (JAS)] and two shoulder seasons [MayJune (MJ) and October-December (OND)]. The key point is that the Hadley circulation $\mathrm{AET}_{\text {eq }}$ dominates both the mean state and the response in all seasons. In addition, the responses of the zonal-mean ITCZ position (PAI) are well correlated to those of the Hadley circulation $\mathrm{AET}_{\mathrm{eq}}$. On the other hand, both the stationary and the transient eddy $\mathrm{AET}_{\mathrm{eq}}$ responses are small in magnitude and largely insensitive to the forcing latitudes through the seasonal cycle.

Likewise, the finding that a dynamic component dominates the annual-mean Hadley circulation $\mathrm{AET}_{\mathrm{eq}}$ response is also resilient to all seasons (Fig. 11); although the thermodynamic response rivals the dynamic response during JAS, the sensitivity of the thermodynamic response does not explain that of the total Hadley circulation $\mathrm{AET}_{\mathrm{eq}}$ responses. One unexpected side note is that the thermodynamic responses are larger (smaller) during the solstice (shoulder) seasons despite small (large) GMS responses (Fig. 9b). While we do not fully understand the underlying cause of this discrepancy, we speculate it is due to the limitations 
(a) The annual cycle of precipitation asymmetry index

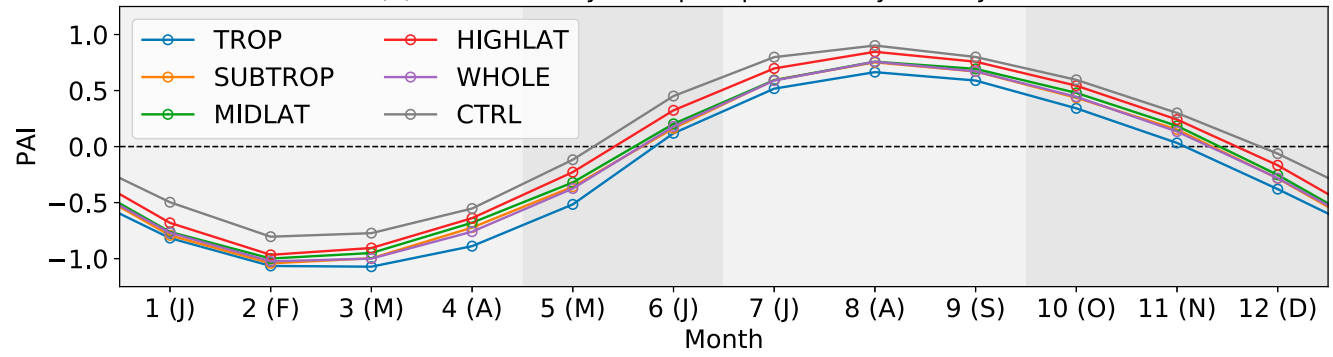

(b) JFMA

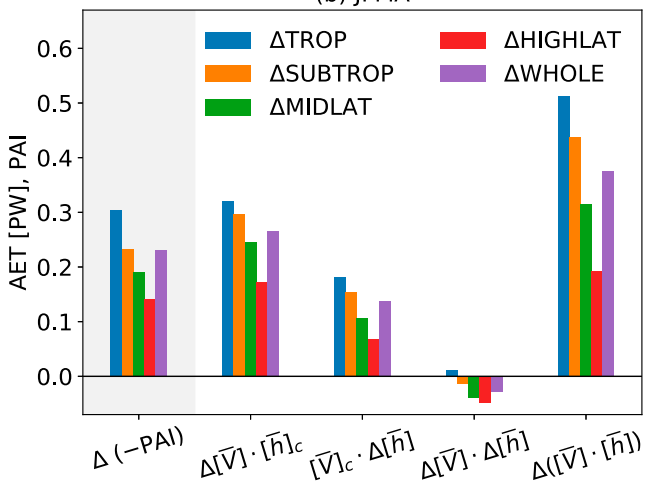

(d) JAS

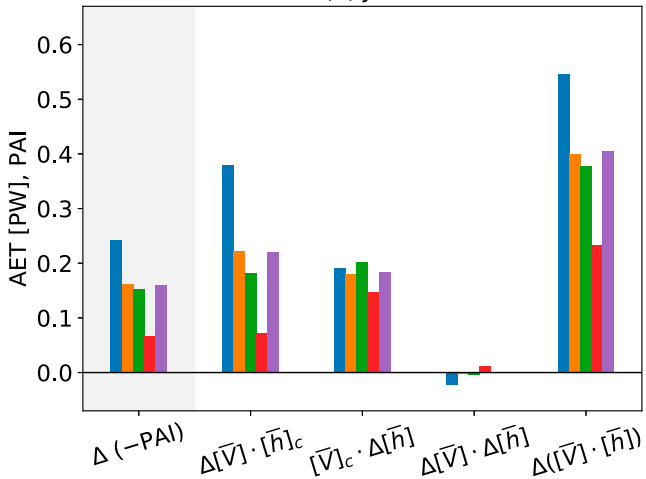

(c) $M J$

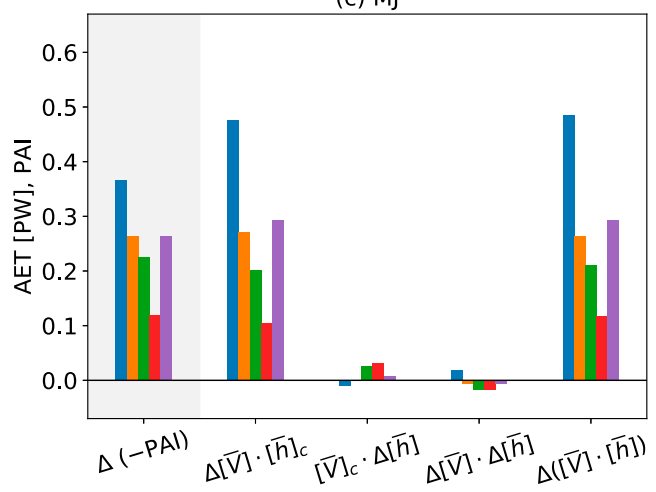

(e) OND

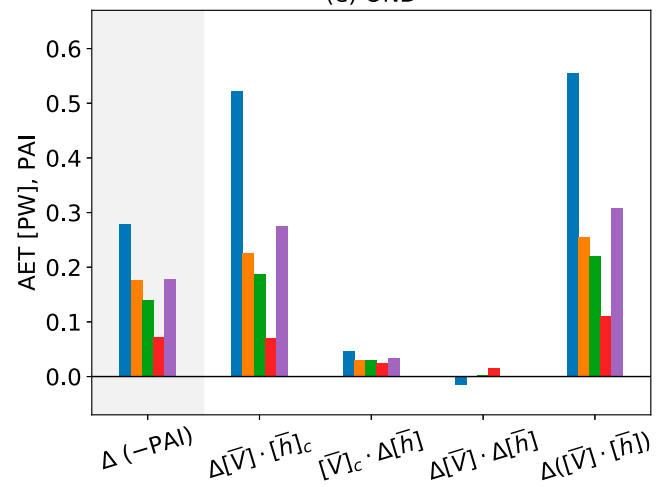

FIG. 11. (a) Climatological annual cycle of the tropical precipitation asymmetry index (PAI). (b-e) As in Figs. 10b-e, but decomposing the mean meridional circulation component of $\operatorname{AET}_{\text {eq }}$ response $\Delta([\bar{V}][\bar{h}])$ into its dynamic $\Delta[\bar{V}][\bar{h}]_{\mathrm{ctrl}}$, thermodynamic $[\bar{V}]_{\mathrm{ctrl}} \Delta[\bar{h}]$, and nonlinear $\Delta[\bar{V}] \Delta[\bar{h}]$ components.

of the simple GMS definition that we have chosen for its interpretability-for instance, subtleties of vertical structures that cannot be captured in this form of GMS, which presumes a simple overturning structure with one lower and one upper branch with opposite directions.

Analogous disparities on such specifics of the seasonal $\mathrm{AET}_{\mathrm{eq}}$ changes were also highlighted by the interesting work of Xiang et al. (2018, hereafter Xiang18), which is relevant to our work. Xiang18 also happened to investigate the energy transport partitioning and zonalmean ITCZ position under a zonally restricted solar forcing at low versus high latitudes, in an independent fully coupled model (GFDL). However, unlike our hemispherically asymmetric forcing, Xiang18 only perturbed one hemisphere. Consistent with our findings, they found that more ocean-centric cross-equatorial energy transport partitioning and reduced ITCZ shifts occurred with their high-latitude forcing compared to a low-latitude forcing. However, the details of the $\mathrm{AET}_{\mathrm{eq}}$ responses appear to have been rather different from our results. The most important difference is that Xiang18 found an energetic framework to be inapplicable, whereas we have shown it works well in our study. For example, Xiang18 showed 1) that the total $\mathrm{AET}_{\mathrm{eq}}$ response during the peak phase of ITCZ (boreal winter) was dominated by the transient eddy component under both low- and high-latitude forcing (this is not true in all 
(a)

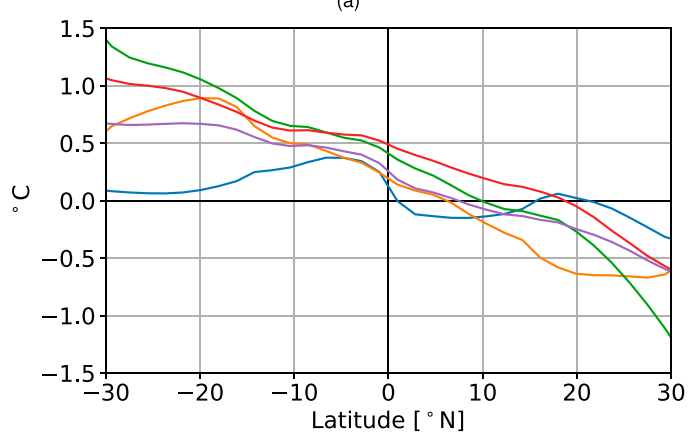

(b)

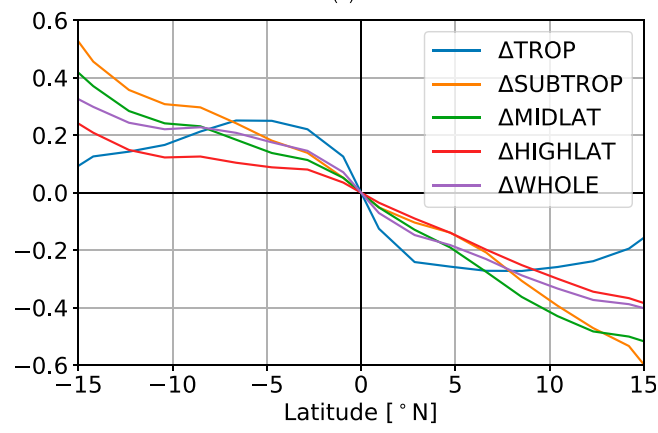

FIG. 12. The climatological annual-mean, zonal-mean profile of (a) SST response between $30^{\circ} \mathrm{S}$ and $30^{\circ} \mathrm{N}$ and (b) SST response after subtracting the equatorial $\left(0^{\circ} \mathrm{N}\right)$ SST response between $15^{\circ} \mathrm{S}$ and $15^{\circ} \mathrm{N}$.

seasons in our simulation; Figs. 10b-e) and 2) that the Hadley circulation $\mathrm{AET}_{\mathrm{eq}}$ was significantly influenced by a thermodynamic response component linked to GMS changes (this is also not true in our simulations; Figs. 11b-e; during JFMA and JAS the thermodynamic responses becomes nontrivial, but the sensitivity of the total responses is led by that of the dynamic responses in all seasons in our experiment). With further analysis of the latent energy budget and the vertical structure of Hadley cell response, Xiang18 argued that the SST changes, which control the boundary layer moisture convergence, caused the ITCZ shift in their simulations, independent of an energetic framework view. As in Xiang18, the responses of the meridional SST gradient in our experiments are monotonically larger for a lowerlatitude forcing (Fig. 12b), while the responses of mean tropical SST are smaller for a lower-latitude forcing experiment (Fig. 12a). But, having found few issues with applying an energetic framework in our experiment, it is still debatable whether those SST gradients should be viewed as a more fundamental root cause for the zonalmean ITCZ shift via causing boundary layer convergence (Lindzen and Nigam 1987; Chiang et al. 2001; Back and Bretherton 2009; Xiang18) versus the alternate explanation that the SST may simply have had to turn out this way to mediate a surface energy balance response that is more fundamentally controlled by the anomalous atmospheric energy budget (transport) (Neelin and Held 1987; Kang et al. 2008, 2009; Kang and Held 2012). This is not to say that feedbacks with equatorial SST gradients and ocean dynamics are irrelevant to the details of our response, especially for TROP, which directly forces the equatorial region. Further analysis of the ocean mixed layer heat budget during the initial transient state would be required to understand the tropical SST pattern formation in response to extratropical forcings.

In short, we have remarked on a few interesting points of contrast in our results versus those of Xiang18. Some of these dissimilarities may stem from the difference of our forcing design (e.g., one hemisphere in Xiang18, as in ETINMIP, versus equal-opposite asymmetric pairs across hemispheres in ours; differences in forcing magnitude; and the seasonality of forcing) and/or simply be related to the model formulation difference. We believe a focus on the above nodes of interesting comparison within the ongoing model intercomparison project, ETINMIP, may help clarify the role of the model diversities and some aspects of forcing design (location) to the simulation results. Still, further studies are required to fully understand the role of forcing specifics (e.g., the seasonality, magnitude, and net perturbation), which are not fully sampled by the current ETINMIP scope.

\section{b. SST responses and radiative feedbacks}

The many internal feedbacks in our experiments have led to behaviors worth contrasting against the intuition gained from previous work that has used slab-ocean modeling setups, which would not have predicted them. For instance, using a slab-ocean coupled GCM forced by a prescribed oceanic energy transport, Seo et al. (2014) showed an amplifying TOA energy imbalance and hence a larger ITCZ shift with higher-latitude perturbations, and explained this as a result of net positive SST-low cloud and SST-outgoing longwave radiation (OLR) feedbacks. Despite the fact that similar SSTmediated radiative feedbacks also exist in our study, the net interhemispheric TOA energy imbalance is largely insensitive to the forcing latitudes (Figs. 2c and 3). This can be traced to the fact that we observe a much weaker SST response magnitude (Fig. 13a) in our more heavily buffered system. For instance, our SST response for HIGHLAT is about $3 \mathrm{~K}$, but this is an order of magnitude smaller than that of Seo et al. $(20-80 \mathrm{~K}$ in their high-latitude forcing simulations) despite the fact that their forcing magnitude is only 1.64 times larger than in our experiment. A decomposition of the details shows 

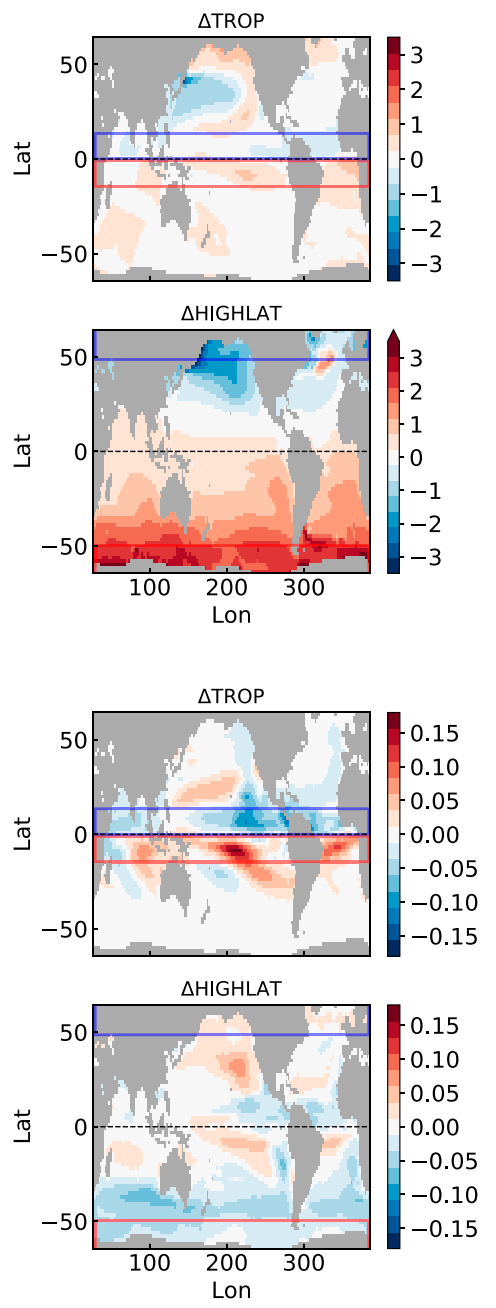

(a) Sea surface temperature

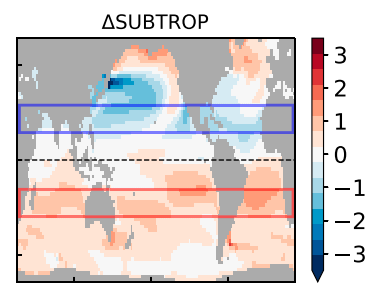

$\triangle$ WHOLE

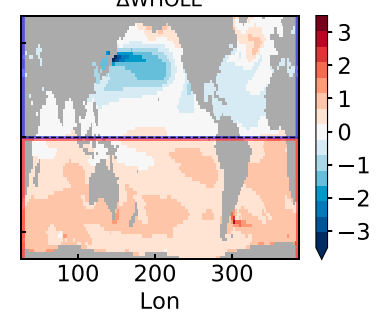

(b) Total cloud fraction
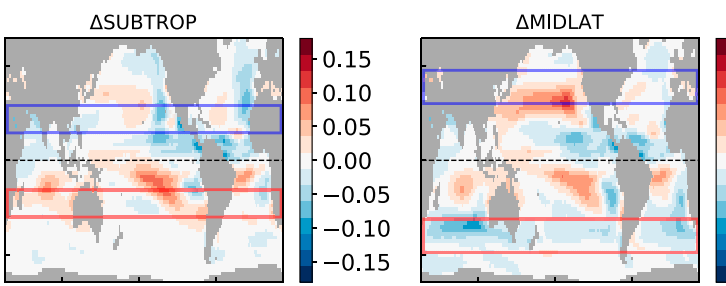

0.15

$-0.10$

$-0.05$

0.00

$-0.05$

$-0.10$

$-0.15$
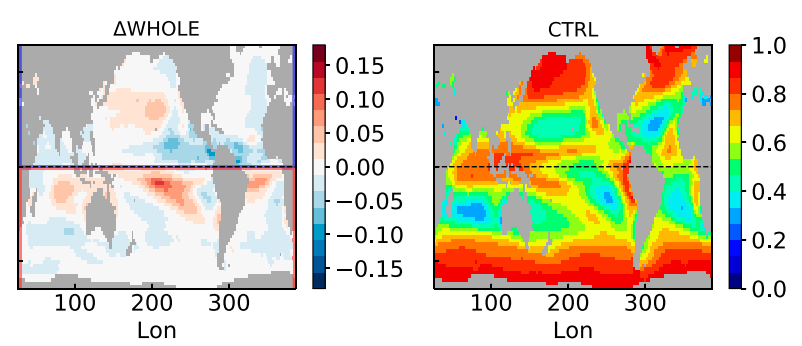

(c) Shortwave cloud radiative effect
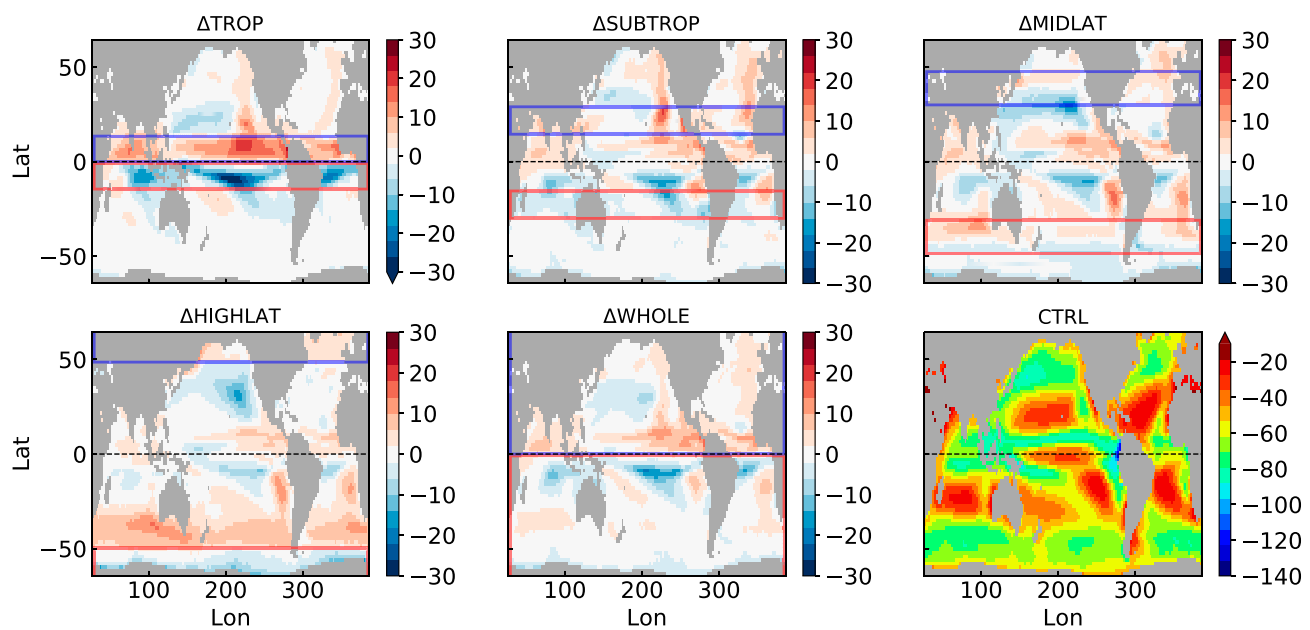

FIG. 13. Responses of (a) sea surface temperature (unit: K), (b) total cloud fraction, and (c) TOA shortwave cloud radiative effect (unit: $\mathrm{W} \mathrm{m}^{-2}$ ), shown as experiment minus control. The baseline values of the control simulation (CTRL) are shown at lower right in (a)-(c). 
that for our high-latitude forcing cases (MIDLAT and HIGHLAT), the negative SST-OLR feedback actually wins over the positive SST-low cloud feedback (Fig. 3). The insensitive TOA energy imbalance despite this net negative SST-low cloud, SST-OLR feedback underscores that important positive feedbacks that were not included in the setup of Seo et al. (2014) ended up playing leading roles in our high-latitude forcing cases. One likely culprit is the positive ice-albedo feedback, which counteracts the negative SST-OLR feedback. It is unclear whether the resilient net TOA response across our simulations is a coincidence or an intrinsic feature of Earth's climate system in the limit of fully interactive radiative/convective/SST feedbacks; this merits more study. Regardless, our findings about partitioning do not depend on the net TOA response magnitude having turned out this way (Fig. 7 and Fig. S6).

Meanwhile, the weak SST responses (compared to the slab ocean simulations) in our simulations highlight the importance of the ocean circulation's role in the global energy budget. Ocean dynamics limit excessive local storage of heat near the surface by redistributing it vertically and horizontally. We have focused on the striking role of overturning circulations in this regard, but the role of gyre circulations would also be an interesting direction for future work to further understand the ocean's role in the energy transport partitioning and the ITCZ shift buffering. While the subtropical gyre circulations do not participate much in the direct (advective) heat exchange across the equator, they can nonlocally affect both the atmospheric and oceanic column energy budgets via SST-dependent feedbacks, such as through SST-low cloud feedbacks in the subtropics modulated by a subtropical gyre that carries anomalously heated surface water from extratropical forcing locations (Mechoso et al. 2016). Indeed, such a linkage is shown in our experiments (Fig. 13). However, the amplitude of this feedback (and accordingly the role of gyre circulations) might have been underrepresented in our model, since CESM has been shown to have a weak sensitivity of low cloud response to the SST anomalies (Mechoso et al. 2016).

\section{c. Equatorial net energy input}

It is worth commenting on the utility of using a theoretical framework pinned on equatorial atmospheric net energy input $\left(\mathrm{NEI}_{\text {eq }}\right)$ to interpret our simulations. Notably, $\mathrm{NEI}_{\mathrm{eq}}$ has been argued to determine the sensitivity of the latitude of the zonal-mean ITCZ $\left(\phi_{\text {ITCZ }}\right)$ to a given magnitude of $\mathrm{AET}_{\text {eq }}$ perturbation (i.e., $\phi_{\text {ITCZ }} \sim$ $\mathrm{AET}_{\mathrm{eq}} / \mathrm{NEI}_{\mathrm{eq}}$ ) (Bischoff and Schneider 2014). Also, $\mathrm{NEI}_{\mathrm{eq}}$ is known to correlate with the hemispherically symmetric component of tropical precipitation biases including the double-ITCZ bias (Adam et al. 2016, 2018). We hypothesize that variations in the $\mathrm{NEI}_{\mathrm{eq}}$ response to solar forcing do not play a leading role in our experiments based on the quasi-linear relationship between interannual PAI versus global OET $_{\text {eq }}$ responses (Figs. 7d,f). Consistent with this view, the fractional response of $\mathrm{NEI}_{\mathrm{eq}}$ is much smaller than that of $\mathrm{AET}_{\text {eq }}$ (Fig. S7). However, we acknowledge that effects of $\mathrm{NEI}_{\mathrm{eq}}$ are important and may be responsible for the deviation from the linear regression line, since changes in $\mathrm{NEI}_{\mathrm{eq}}$ can cause ITCZ shifts independent of changes in $\mathrm{AET}_{\mathrm{eq}}$ (disregarding potential feedbacks between them).

\section{d. Model diversity}

An obvious limitation of this study is the use of a single climate model, which raises the question of whether similar responses should be expected in other climate models. On the one hand, a satisfying answer on intermodel spread will only be gleaned from a targeted model intercomparison, which will be forthcoming via ETINMIP. This community activity will include analysis of atmosphere-ocean partitioning of the energy transport response to extratropical TOA perturbation. On the other hand, it is also already logical to expect some degree of similar responses to occur across independent models. Despite the fact that the temporal mean structure and variability of the AMOC varies widely among models from phases 3 and 5 of the Coupled Model Intercomparison Project (CMIP3 and CMIP5) (Medhaug and Furevik 2011; Zhang and Wang 2013; Muir and Fedorov 2015), the AMOC's response to differing forms of radiative forcing tends to share a common sign. Across CMIP5 models, anthropogenic $\mathrm{CO}_{2}$ forcing tends to weaken the AMOC (Gregory et al. 2005; Cheng et al. 2013), and volcanic aerosol forcing strengthens it (Ding et al. 2014) while also shifting the ITCZ toward the hemisphere opposite to eruption (Iles and Hegerl 2014). Anthropogenic aerosol forcing has also been shown to strengthen the AMOC across a set of independent studies that used different coupled GCMs, such as GFDL CM2.1 (Delworth and Dixon 2006), CSIRO-Mk2.1 (Cowan and Cai 2013), and HadGEM2-ES (Menary et al. 2013). Especially considering that our TOA solar perturbation shares some similarities to a geographically confined aerosol radiative forcing, these are all reasons to expect that the sensitivity we have shown in CESM might be detectable in other CMIP5-class climate models.

\section{e. Other remarks}

Another limitation of this work is that it does not attempt to fully attribute the mechanistic pathway connecting regional TOA solar forcing to varying degrees of AMOC response. While beyond the scope of this article, 
we view it as an interesting topic worthy of future work via process analysis focused on subducting regions. As expected from our imposed cooling of the North Atlantic, positive regional anomalies of surface ocean density over the Labrador Sea deep water formation region lead AMOC responses in all our experiments (Fig. S8). But the origin of these density perturbations in the Labrador Sea is not immediately obvious, especially in the case of low-latitude forcing experiments where solar perturbations are applied away from the deep water formation regions. Relevant bridge processes are likely to include advection of buoyancy anomalies through subtropical and subpolar gyres and regional meteorological changes via tropical-extratropical teleconnection. On the other hand, we suspect that Southern Hemisphere warming weakens the AMOC, as suggested by the fact that a Southern Hemisphere warming-only experiment slowed AMOC in the recent work of Xiang18. Future work focusing on these mechanistic process chains might help contribute to further understanding of the AMOC-ITCZ nexus.

We have intentionally used idealized, geographically localized forcing bands to probe the coupled system's dynamics. It is natural to wonder to what degree this contributes toward the understanding of the system's sensitivity to more realistic sources of hemispherically asymmetric solar forcing like those produced by some volcanoes, or those that might occur by some forms of geo-engineering. In this context we suggest it may be possible to think of our experiments as akin to Green's functions, or kernels, in which they have some demonstrable additive utility. That is, the results of the WHOLE experiment-wherein we perturb each entire hemisphere at one quarter the local forcing magnitude of the four regional experiments-reproduce to a remarkable degree the linear average of those four experiments' independent responses (e.g., Figs. 2-5). This implies some generality beyond our idealized setup that could be practically relevant to many realistic forcing contexts; the idea of kernels summarizing these dynamics would be worth exploring more.

\section{f. Implications}

Notwithstanding the above limitations, one implication of our results relates to improving tropical rainfall biases in coupled GCMs. Our results, along with several recent coupled GCM studies (Kay et al. 2016; Hawcroft et al. 2017, 2018), seem to challenge the notion that high-latitude cloud radiative biases play a controlling role on biases of tropical precipitation, a view that has been supported by correlations across CMIP5 models (Hwang and Frierson 2013). Our experiments imply the opposite, given that the AMOC response can provide an efficient buffer to ITCZ shifts when hemispherically asymmetric radiative forcing biases are concentrated at high latitudes. The reduction of this oceanic buffering pathway when the same interhemispheric forcing is focused at low latitudes suggests that even a small radiative bias near the tropics might induce a strong atmospheric (ITCZ shift) response. This appears consistent with the findings of Xiang et al. (2017) that argued, across CMIP5 models, that the degree of the double ITCZ bias of coupled models is better predicted by the hemispheric asymmetry of their net TOA shortwave fluxes near the tropics in atmosphere-only simulations than by those in the extratropics. It also evokes the findings of Mechoso et al. (2016), who showed stratocumulus cloud biases in the subtropics can overwhelm modifications to Southern Ocean radiative forcing. Together, these results support renewed focus on improving low-latitude radiation biases toward improving tropical precipitation in GCMs.

\section{Conclusions}

We have shown results from a comprehensive global climate model revealing that the AMOC can be especially important in setting the degree to which ocean dynamics act to damp radiatively forced migrations of the zonal-mean ITCZ via modulating the energy transport partitioning between ocean and atmosphere. This effect becomes strong when a hemispherically asymmetric pair of discrete solar forcing bands is focused at high latitudes, highlighting the importance of the meridional distribution of shortwave radiative forcing in such dynamics. The main implication is that ongoing attempts to develop ITCZ migration theory that include the role of buffering by ocean dynamics may ultimately depend on a satisfying theory for the AMOC's response to radiative forcing, and its links to the ITCZ. Another practical implication for near-term GCM development is that fixing low-latitude TOA radiative biases in climate models might be a more practical strategy toward improving tropical rainfall biases than fixing highlatitude biases.

Acknowledgments. We would like to acknowledge insightful discussions with François Primeau over the course of this research. We also acknowledge Chris Bretherton, Paola Cecci, Gokhan Danabasoglu, Dargan Frierson, Matt Hawcroft, Isaac Held, Sarah Kang, Jennifer Kay, Carlos Mechoso, Timothy Myers, Michael Prather, Brian Rose, Hansi Singh, Tapio Schneider, Matthew Thomas, Rachel White, Matthew Woelfle, and Jin-Yi Yu for stimulating conversation on this work. We thank three anonymous reviewers for their constructive 
suggestions that made this manuscript much clearer. This work was funded by the National Science Foundation AGS-1419518. MSP acknowledges additional partial support from NASA MIRO (Grant NNX15AQ06A). Model simulations were done on Yellowstone (ark:/85065/d7wd3xhc) provided by the Computational and Information Systems Laboratory of the U.S. National Center for Atmospheric Research, sponsored by the National Science Foundation, and the Extreme Science and Engineering Discovery Environment (XSEDE), which is supported by NSF Grant ACI-1548562, under allocation TG-ATM120034.

\section{APPENDIX}

\section{Calculation of Atmospheric Mass Flux}

Our model simulations did not directly accumulate the time-mean atmospheric meridional mass flux $\overline{v d p / g}$. Given that the eddy component $\overline{v^{\prime} d p^{\prime}}$ is a nontrivial contributor to the zonal-mean meridional mass flux, this complicates the estimation of AET, especially at midlatitudes. Accordingly, we make an ad hoc correction to $v$ by introducing $v_{\mathrm{c}}$ that satisfies mass conservation $\left(\left\{\overline{\boldsymbol{v}_{c}} \overline{d p}\right\}=0\right.$, where curly brackets denote zonal and vertical averaging). The term $v_{c}$ is obtained by subtracting the density-weighted zonal and vertical mean of $v$ at each latitude, that is, $v_{c}=v-\{v d p\} /\{d p\}$. This follows Hill et al. (2015) and Yang et al. (2015), who found the same correction to be useful in the face of interpolation errors that can also mask the fact that the atmospheric model does in fact obey zonal-mean mass conservation.

\section{REFERENCES}

Adam, O., T. Schneider, F. Brient, and T. Bischoff, 2016: Relation of the double-ITCZ bias to the atmospheric energy budget in climate models. Geophys. Res. Lett., 43, 7670-7677, https://doi.org/10.1002/ 2016GL069465.

,-- , and -2018 : Regional and seasonal variations of the double-ITCZ bias in CMIP5 models. Climate Dyn., 51, 101117, https://doi.org/10.1007/s00382-017-3909-1.

Allen, R. J., 2015: A 21st century northward tropical precipitation shift caused by future anthropogenic aerosol reductions. J. Geophys. Res. Atmos., 120, 9087-9102, https://doi.org/ 10.1002/2015JD023623.

Back, L. E., and C. S. Bretherton, 2009: On the relationship between SST gradients, boundary layer winds, and convergence over the tropical oceans. J. Climate, 22, 4182-4196, https:// doi.org/10.1175/2009JCLI2392.1.

Bischoff, T., and T. Schneider, 2014: Energetic constraints on the position of the intertropical convergence zone. J. Climate, 27, 4937-4951, https://doi.org/10.1175/JCLI-D-13-00650.1.

Bjerknes, J., 1964: Atlantic air-sea interaction. Advances in Geophysics, Vol. 10, Academic Press, 1-82, https://doi.org/10.1016/ S0065-2687(08)60005-9.
Broccoli, A., K. Dahl, and R. Stouffer, 2006: Response of the ITCZ to Northern Hemisphere cooling. Geophys. Res. Lett., 33, L01702, https://doi.org/10.1029/2005GL024546.

Buckley, M., and J. Marshall, 2016: Observations, inferences, and mechanisms of the Atlantic meridional overturning circulation: A review. Rev. Geophys., 54, 5-63, https://doi.org/10.1002/ 2015RG000493.

Chang, P., and Coauthors, 2008: Oceanic link between abrupt changes in the North Atlantic Ocean and the African monsoon. Nat. Geosci., 1, 444-448, https://doi.org/10.1038/ngeo218.

Cheng, W., J. C. H. Chiang, and D. Zhang, 2013: Atlantic meridional overturning circulation (AMOC) in CMIP5 models: RCP and historical simulations. J. Climate, 26, 7187-7197, https:// doi.org/10.1175/JCLI-D-12-00496.1.

Chiang, J. C., and C. M. Bitz, 2005: Influence of high latitude ice cover on the marine intertropical convergence zone. Climate Dyn., 25, 477-496, https://doi.org/10.1007/s00382-005-0040-5.

_ S. E. Zebiak, and M. A. Cane, 2001: Relative roles of elevated heating and surface temperature gradients in driving anomalous surface winds over tropical oceans. J. Atmos. Sci., 58, 1371-1394, https://doi.org/10.1175/1520-0469(2001)058<1371: RROEHA $>2.0 . \mathrm{CO} ; 2$.

Cowan, T., and W. Cai, 2013: The response of the large-scale ocean circulation to 20th century Asian and non-Asian aerosols. Geophys. Res. Lett., 40, 2761-2767, https://doi.org/10.1002/grl.50587.

Cunningham, S. A., and Coauthors, 2007: Temporal variability of the Atlantic meridional overturning circulation at $26.5^{\circ} \mathrm{N}$. Science, 317, 935-938, https://doi.org/10.1126/science.1141304.

Czaja, A., and J. Marshall, 2006: The partitioning of poleward heat transport between the atmosphere and ocean. J. Atmos. Sci., 63, 1498-1511, https://doi.org/10.1175/JAS3695.1.

Danabasoglu, G., and Coauthors, 2014: North Atlantic simulations in Coordinated Ocean-Ice Reference Experiments phase II (CORE-II). Part I: Mean states. Ocean Modell., 73, 76-107, https://doi.org/10.1016/j.ocemod.2013.10.005.

Delworth, T. L., and K. W. Dixon, 2006: Have anthropogenic aerosols delayed a greenhouse gas-induced weakening of the North Atlantic thermohaline circulation? Geophys. Res. Lett., 33, L02606, https://doi.org/10.1029/2005GL024980.

Ding, Y., J. A. Carton, G. A. Chepurin, G. Stenchikov, A. Robock, L. T. Sentman, and J. P. Krasting, 2014: Ocean response to volcanic eruptions in Coupled Model Intercomparison Project 5 simulations. J. Geophys. Res. Oceans, 119, 5622-5637, https://doi.org/10.1002/2013JC009780.

Donohoe, A., J. Marshall, D. Ferreira, and D. McGee, 2013: The relationship between ITCZ location and cross-equatorial atmospheric heat transport: From the seasonal cycle to the last glacial maximum. J. Climate, 26, 3597-3618, https://doi.org/ 10.1175/JCLI-D-12-00467.1.

,,,--- K. Armour, and D. McGee, 2014: The interannual variability of tropical precipitation and interhemispheric energy transport. J. Climate, 27, 3377-3392, https://doi.org/ 10.1175/JCLI-D-13-00499.1.

Drijfhout, S. S., 2010: The atmospheric response to a thermohaline circulation collapse: Scaling relations for the Hadley circulation and the response in a coupled climate model. J. Climate, 23, 757-774, https://doi.org/10.1175/2009JCLI3159.1.

Frierson, D. M., 2007: The dynamics of idealized convection schemes and their effect on the zonally averaged tropical circulation. J. Atmos. Sci., 64, 1959-1976, https://doi.org/10.1175/JAS3935.1.

_ _ and Coauthors, 2013: Contribution of ocean overturning circulation to tropical rainfall peak in the Northern Hemisphere. Nat. Geosci., 6, 940-944, https://doi.org/10.1038/ngeo1987. 
Fučkar, N. S., S. Xie, R. Farneti, E. A. Maroon, and D. M. Frierson, 2013: Influence of the extratropical ocean circulation on the intertropical convergence zone in an idealized coupled general circulation model. J. Climate, 26, 4612-4629, https://doi.org/ 10.1175/JCLI-D-12-00294.1.

Green, B., and J. Marshall, 2017: Coupling of trade winds with ocean circulation damps ITCZ shifts. J. Climate, 30, 43954411, https://doi.org/10.1175/JCLI-D-16-0818.1.

Gregory, J., and Coauthors, 2005: A model intercomparison of changes in the Atlantic thermohaline circulation in response to increasing atmospheric $\mathrm{CO}_{2}$ concentration. Geophys. Res. Lett., 32, L12703, https://doi.org/10.1029/2005GL023209.

Hawcroft, M., J. Haywood, M. Collins, A. Jones, A. C. Jones, and G. Stephens, 2017: Southern Ocean albedo, inter-hemispheric energy transports and the double ITCZ: Global impacts of biases in a coupled model. Climate Dyn., 48, 2279-2295, https://doi.org/10.1007/s00382-016-3205-5.

,,--- and,- 2018 : The contrasting climate response to tropical and extratropical energy perturbations. Climate Dyn., 51, 3231-3249, https://doi.org/10.1007/s00382-018-4076-8.

Haywood, J. M., and Coauthors, 2016: The impact of equilibrating hemispheric albedos on tropical performance in the HadGEM2ES coupled climate model. Geophys. Res. Lett., 43, 395-403, https://doi.org/10.1002/2015GL066903.

Heaviside, C., and A. Czaja, 2013: Deconstructing the Hadley cell heat transport. Quart. J. Roy. Meteor. Soc., 139, 2181-2189, https://doi.org/10.1002/qj.2085.

Held, I., 2001: The partitioning of the poleward energy transport between the tropical ocean and atmosphere. J. Atmos. Sci., 58, 943-948, https://doi.org/10.1175/1520-0469(2001)058<0943: TPOTPE $>2.0 . \mathrm{CO} ; 2$.

Hill, S. A., Y. Ming, and I. M. Held, 2015: Mechanisms of forced tropical meridional energy flux change. J. Climate, 28, 17251742, https://doi.org/10.1175/JCLI-D-14-00165.1.

Hurrell, J. W., and Coauthors, 2013: The Community Earth System Model: A framework for collaborative research. Bull. Amer. Meteor. Soc., 94, 1339-1360, https://doi.org/ 10.1175/BAMS-D-12-00121.1.

Hwang, Y., and D. Frierson, 2013: Link between the doubleintertropical convergence zone problem and cloud biases over the Southern Ocean. Proc. Natl. Acad. Sci. USA, 110, 4935 4940, https://doi.org/10.1073/pnas.1213302110.

Iles, C., and G. Hegerl, 2014: The global precipitation response to volcanic eruptions in the CMIP5 models. Environ. Res. Lett., 9, 104012, https://doi.org/10.1088/1748-9326/9/10/104012.

Jayne, S. R., and J. Marotzke, 2002: The oceanic eddy heat transport. J. Phys. Oceanogr., 32, 3328-3345, https://doi.org/ 10.1175/1520-0485(2002)032<3328:TOEHT >2.0.CO;2.

Kang, S. M., and I. M. Held, 2012: Tropical precipitation, SSTs and the surface energy budget: A zonally symmetric perspective. Climate Dyn., 38, 1917-1924, https://doi.org/10.1007/s00382 011-1048-7.

,-- D. M. Frierson, and M. Zhao, 2008: The response of the ITCZ to extratropical thermal forcing: Idealized slab-ocean experiments with a GCM. J. Climate, 21, 3521-3532, https:// doi.org/10.1175/2007JCLI2146.1.

_, D. M. Frierson, and I. M. Held, 2009: The tropical response to extratropical thermal forcing in an idealized GCM: The importance of radiative feedbacks and convective parameterization. J. Atmos. Sci., 66, 2812-2827, https://doi.org/10.1175/ 2009JAS2924.1.

_- Y. Shin, and S. Xie, 2018: Extratropical forcing and tropical rainfall distribution: Energetics framework and ocean Ekman advection. npj Climate Atmos. Sci., 1, 20172, https://doi.org/ 10.1038/s41612-017-0004-6.

Kay, J. E., C. Wall, V. Yettella, B. Medeiros, C. Hannay, P. Caldwell, and C. Bitz, 2016: Global climate impacts of fixing the Southern Ocean shortwave radiation bias in the Community Earth System Model (CESM). J. Climate, 29, 4617-4636, https:// doi.org/10.1175/JCLI-D-15-0358.1.

Li, G., and S.-P. Xie, 2014: Tropical biases in CMIP5 multimodel ensemble: The excessive equatorial Pacific cold tongue and double ITCZ problems. J. Climate, 27, 1765-1780, https://doi. org/10.1175/JCLI-D-13-00337.1.

Lin, J., 2007: The double-ITCZ problem in IPCC AR4 coupled GCMs: Ocean-atmosphere feedback analysis. J. Climate, 20, 4497-4525, https://doi.org/10.1175/JCLI4272.1.

Lindzen, R. S., and S. Nigam, 1987: On the role of sea surface temperature gradients in forcing low-level winds and convergence in the tropics. J. Atmos. Sci., 44, 2418-2436, https://doi.org/10.1175/ 1520-0469(1987)044<2418:OTROSS >2.0.CO;2.

Liu, Z., and S. G. H. Philander, 1995: How different wind stress patterns affect the tropical-subtropical circulations of the upper ocean. J. Phys. Oceanogr., 25, 449-462, https://doi.org/ 10.1175/1520-0485(1995)025<0449:HDWSPA>2.0.CO;2.

Manabe, S., and R. Stouffer, 1995: Simulation of abrupt climate change induced by freshwater input to the North Atlantic Ocean. Nature, 378, 165-167, https://doi.org/10.1038/378165a0.

Marshall, J., A. Donohoe, D. Ferreira, and D. McGee, 2014: The ocean's role in setting the mean position of the inter-tropical convergence zone. Climate Dyn., 42, 1967-1979, https://doi.org/ 10.1007/s00382-013-1767-z

McCreary, J. P., and P. Lu, 1994: Interaction between the subtropical and equatorial ocean circulations: The subtropical cell. J. Phys. Oceanogr., 24, 466-497, https://doi.org/10.1175/ 1520-0485(1994)024<0466:IBTSAE > 2.0.CO;2.

McFarlane, A. A., and D. M. W. Frierson, 2017: The role of ocean fluxes and radiative forcings in determining tropical rainfall shifts in RCP8.5 simulations. Geophys. Res. Lett., 44, 86568664, https://doi.org/10.1002/2017GL074473.

Mechoso, C., and Coauthors, 1995: The seasonal cycle over the tropical Pacific in coupled ocean-atmosphere general circulation models. Mon. Wea. Rev., 123, 2825-2838, https://doi.org/ 10.1175/1520-0493(1995)123<2825:TSCOTT >2.0.CO;2.

— , and Coauthors, 2016: Can reducing the incoming energy flux over the Southern Ocean in a CGCM improve its simulation of tropical climate? Geophys. Res. Lett., 43, 11 057-11063, https://doi.org/10.1002/2016GL071150.

Medhaug, I., and T. Furevik, 2011: North Atlantic 20th century multidecadal variability in coupled climate models: Sea surface temperature and ocean overturning circulation. Ocean Sci., 7, 389-404, https://doi.org/10.5194/os-7-389-2011.

Menary, M., and Coauthors, 2013: Mechanisms of aerosol-forced AMOC variability in a state of the art climate model. J. Geophys. Res. Oceans, 118, 2087-2096, https://doi.org/ 10.1002/jgrc. 20178

Merlis, T. M., T. Schneider, S. Bordoni, and I. Eisenman, 2013: Hadley circulation response to orbital precession. Part I: Aquaplanets. J. Climate, 26, 740-753, https://doi.org/10.1175/ JCLI-D-11-00716.1.

Miyama, T., M. Julian, T. Jensen, J. Loschnigg, S. Godfrey, and A. Ishida, 2003: Structure and dynamics of the Indian-Ocean cross-equatorial cell. Deep-Sea Res. II, 50, 2023-2047, https:// doi.org/10.1016/S0967-0645(03)00044-4.

Muir, L., and A. Fedorov, 2015: How the AMOC affects ocean temperatures on decadal to centennial timescales: The North 
Atlantic versus an interhemispheric seesaw. Climate Dyn., 45, 151-160, https://doi.org/10.1007/s00382-014-2443-7.

Neelin, J., and I. Held, 1987: Modeling tropical convergence based on the moist static energy budget. Mon. Wea. Rev., 115, 3-12, https:// doi.org/10.1175/1520-0493(1987)115<0003:MTCBOT>2.0.CO;2.

Nonaka, M., S. Xie, and J. P. McCreary, 2002: Decadal variations in the subtropical cells and equatorial Pacific SST. Geophys. Res. Lett., 29, 1116, https://doi.org/10.1029/2001GL013717.

Pillar, H. R., P. Heimbach, H. L. Johnson, and D. P. Marshall, 2016: Dynamical attribution of recent variability in Atlantic overturning. J. Climate, 29, 3339-3352, https://doi.org/10.1175/JCLI-D-15-0727.1.

Raymond, D. J., S. L. Sessions, A. H. Sobel, and Z. Fuchs, 2009: The mechanics of gross moist stability. J. Adv. Model. Earth Syst., 1 (9), https://doi.org/10.3894/JAMES.2009.1.9.

Roberts, W. G., P. Valdes, and J. Singarayer, 2017: Can energy fluxes be used to interpret glacial/interglacial precipitation changes in the tropics? Geophys. Res. Lett., 44, 6373-6382, https://doi.org/10.1002/2017GL073103.

Rotstayn, L., M. Collier, and J. Luo, 2015: Effects of declining aerosols on projections of zonally averaged tropical precipitation. Environ. Res., 10, 044018, https://doi.org/10.1088/1748-9326/10/4/044018.j

Schneider, T., 2017: Feedback of atmosphere-ocean coupling on shifts of the intertropical convergence zone. Geophys. Res. Lett., 44, 11 644-11 653, https://doi.org/10.1002/2017GL075817.

— the intertropical convergence zone. Nature, 513, 45-53, https:// doi.org/10.1038/nature13636.

Schott, F., W. Wang, and D. Stammer, 2007: Variability of Pacific subtropical cells in the 50-year ECCO assimilation. Geophys. Res. Lett., 34, L05604, https://doi.org/10.1029/2006GL028478.

Seo, J., S. Kang, and D. Frierson, 2014: Sensitivity of intertropical convergence zone movement to the latitudinal position of thermal forcing. J. Climate, 27, 3035-3042, https://doi.org/ 10.1175/JCLI-D-13-00691.1.

,$- \ldots$, and T. Merlis, 2017: A model intercomparison of the tropical precipitation response to a $\mathrm{CO}_{2}$ doubling in aquaplanet simulations. Geophys. Res. Lett., 44, 993-1000, https:// doi.org/10.1002/2016GL072347.

Shaw, T., A. Voigt, S. Kang, and J. Seo, 2015: Response of the intertropical convergence zone to zonally asymmetric subtropical surface forcings. Geophys. Res. Lett., 42, 9961-9969, https://doi.org/10.1002/2015GL066027.

Smith, R., and Coauthors, 2010: The Parallel Ocean Program (POP) reference manual: Ocean component of the Community Climate System Model (CCSM) and Community Earth System Model (CESM). Los Alamos National Laboratory Rep. LAUR-10-01853, 141 pp.

Stanfield, R. E., and Coauthors, 2016: A quantitative assessment of precipitation associated with the ITCZ in the CMIP5 GCM simulations. Climate Dyn., 47, 1863-1880, https://doi.org/ 10.1007/s00382-015-2937-y.

Stone, P. H., 1978: Constraints on dynamical transports of energy on a spherical planet. Dyn. Atmos. Oceans, 2, 123-139, https:// doi.org/10.1016/0377-0265(78)90006-4.

Thomas, M., and A. Fedorov, 2017: The eastern subtropical Pacific origin of the equatorial cold bias in climate models: A Lagrangian perspective. J. Climate, 30, 5885-5900, https:// doi.org/10.1175/JCLI-D-16-0819.1.

Tomas, R. A., C. Deser, and L. Sun, 2016: The role of ocean heat transport in the global climate response to projected Arctic sea ice loss. J. Climate, 29, 6841-6859, https://doi.org/10.1175/ JCLI-D-15-0651.1.

Trenberth, K. E., and A. Solomon, 1994: The global heat balance: Heat transports in the atmosphere and ocean. Climate Dyn., 10, 107-134, https://doi.org/10.1007/BF00210625.

Vallis, G. K., and R. Farneti, 2009: Meridional energy transport in the coupled atmosphere-ocean system: Scaling and numerical experiments. Quart. J. Roy. Meteor. Soc., 135, 1643-1660, https://doi.org/10.1002/qj.498.

Vellinga, M., and R. Wood, 2002: Global climatic impacts of a collapse of the Atlantic thermohaline circulation. Climatic Change, 54, 251-267, https://doi.org/10.1023/A:1016168827653.

Vonder Haar, T. H., and A. H. Oort, 1973: New estimate of annual poleward energy transport by Northern Hemisphere oceans. J. Phys. Oceanogr., 3, 169-172, https://doi.org/10.1175/15200485(1973)003<0169:NEOAPE > 2.0.CO;2.

Wei, H., and S. Bordoni, 2018: Energetic constraints on the ITCZ position in idealized simulations with a seasonal cycle. J. $A d v$. Model. Earth Syst., 10, 1708-1725, https://doi.org/10.1029/ 2018MS001313.

Woelfle, M., S. Yu, C. Bretherton, and M. Pritchard, 2018: Sensitivity of coupled tropical Pacific model biases to convective parameterization in CESM1. J. Adv. Model. Earth Syst., 10, 126-144, https://doi.org/10.1002/2017MS001176.

Wunsch, C., 2005: The total meridional heat flux and its oceanic and atmospheric partition. J. Climate, 18, 4374-4380, https:// doi.org/10.1175/JCLI3539.1.

Xiang, B., M. Zhao, I. Held, and J. Golaz, 2017: Predicting the severity of spurious "double ITCZ" problem in CMIP5 coupled models from AMIP simulations. Geophys. Res. Lett., 44, 1520-1527, https://doi.org/10.1002/2016GL071992.

- - - Y. Ming, W. Yu, and S. M. Kang, 2018: Contrasting impacts of radiative forcing in the Southern Ocean versus southern tropics on ITCZ position and energy transport in one GFDL climate model. J. Climate, 31, 5609-5628, https://doi.org/ 10.1175/JCLI-D-17-0566.1.

Yang, H., Q. Li, K. Wang, Y. Sun, and D. Sun, 2015: Decomposing the meridional heat transport in the climate system. Climate Dyn., 44, 2751-2768, https://doi.org/10.1007/s00382-014-2380-5. , Q. Wen, J. Yao, and Y. Wang, 2017: Bjerknes compensation in meridional heat transport under freshwater forcing and the role of climate feedback. J. Climate, 30, 5167-5185, https://doi.org/ 10.1175/JCLI-D-16-0824.1.

Zhang, L., and C. Wang, 2013: Multidecadal North Atlantic sea surface temperature and Atlantic meridional overturning circulation variability in CMIP5 historical simulations. J. Geophys. Res. Oceans, 118, 5772-5791, https://doi.org/10.1002/ jgrc.20390.

Zhang, R., and T. Delworth, 2005: Simulated tropical response to a substantial weakening of the Atlantic thermohaline circulation. J. Climate, 18, 1853-1860, https://doi.org/10.1175/ JCLI3460.1.

_ S. Kang, and I. Held, 2010: Sensitivity of climate change induced by the weakening of the Atlantic meridional overturning circulation to cloud feedback. J. Climate, 23, 378-389, https://doi.org/10.1175/2009JCLI3118.1.

Zhang, X., H. Liu, and M. Zhang, 2015: Double ITCZ in coupled ocean-atmosphere models: From CMIP3 to CMIP5. Geophys. Res. Lett., 42, 8651-8659, https://doi.org/10.1002/ 2015 GL065973. 